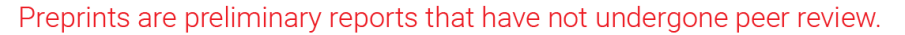 They should not be considered conclusive, used to inform clinical practice, or referenced by the media as validated information. \\ Longwall Face Roof Disaster Prediction Algorithm Based on Data Model Driving
}

\section{Yihui Pang ( $\triangle$ pangyihui@tdkcsj.com )}

coal mining \& design branch, China coal research institute https://orcid.org/0000-0002-7126-9029

\section{Guofa Wang}

CCTEG: China Coal Technology and Engineering Group Corp

\section{Hongbo Wang}

China University of Mining and Technology - Beijing Campus

\section{Research}

Keywords: data model, roof disaster, hydraulic support, characteristic parameter, intelligent prediction

Posted Date: January 15th, 2021

DOl: https://doi.org/10.21203/rs.3.rs-141841/v1

License: (1) This work is licensed under a Creative Commons Attribution 4.0 International License. Read Full License

Version of Record: A version of this preprint was published at International Journal of Coal Science \&amp; Technology on March 10th, 2022. See the published version at https://doi.org/10.1007/s40789022-00474-4. 


\title{
Longwall face roof disaster prediction algorithm based on data
}

\section{model driving}

\author{
Yihui Pang*, Guofa Wang, Hong bo Wang \\ 1. Coal Mining Research Institute Co., Ltd of CCTEG, Beijing 100013, China; 2. Coal Mining and Designing Department, \\ Tiandi Science \& Technology Co. Ltd, Beijing 100013, China; 3. Coal Mining Branch, China Coal Research Institute, Beijing \\ 100013, China; 4. China University of Mining and Technology-Beijing, School of Energy and Mining Engineering, Beijing \\ 100083, China.
}

(C) The Editorial Office of Journal of Coal Science and Technology and Springer-Verlag Berlin Heidelberg 2014

\begin{abstract}
Hydraulic support is the main equipment used for surrounding rock control at fully mechanized mining face. Data such as load and posture of hydraulic support are important basis for predicting roof disasters. This paper summarized and analyzed the status of coal mine safety accidents and the main influencing factors of roof disasters, and proposed the monitoring information characteristic parameters of roof disasters based on support posture-load changes. According to the monitoring load data of the Yanghuopan coal mine, the data feature decomposition method was used to effectively extract the trend item and cycle period item of the load, and the period weighting characteristics of the longwall face was obtained. Some various algorithms were used to model and analyze the monitoring data, which can better realize the single point prediction and the prediction of one support cycle. The accuracy of different algorithms was evaluated. Different data models had better single point prediction effects on the support load. SARIMA model was better than ARIMA model for load prediction in one support cycle, but the prediction effect of these two algorithms in one fracture cycle was poor. Therefore, we proposed a hydraulic support load prediction method based on multiple data cutting and hydraulic support load template library, and constructed the technical framework of roof disaster intelligent prediction platform based on this method, which can perform the prediction and early warning of roof disaster according to the load and posture monitoring information of hydraulic support.
\end{abstract}

Keywords data model, roof disaster, hydraulic support, characteristic parameter, intelligent prediction

\section{Introduction}

Longwall mining is the most common coal mining technology in China. The excavation breaks the original stress balance in the surrounding rock, which makes the overlying strata experience periodic fracture instability. Hydraulic support is the main equipment for surrounding rock control of longwall mining face. The load, posture and other support information of hydraulic support can represent the roof movement to a certain extent [1-3]. With the increase of mining height, mining intensity and mining depth year by year, it is difficult to control the surrounding rock of longwall face, and it is very easy to occur coal wall spalling, roof falling, support crushing and other accidents. According to the change law of the support state, it is an effective technical way to realize the prevention and control of the roof disaster by predicting the roof weighting and the accidents such as roof falling and support crushing.

Understanding the coupling relationship between hydraulic support and surrounding rock is therefore of great importance for ground control and roof disaster forecasting. Numerous studies have been carried out to study the problem of surrounding rock control and roof disaster prevention. Qian and colleagues [4-6] put forward the theory of "voussoir beam" and "key stratum", which formed the foundational mechanics models for ground pressure and strata control in longwall face. Song and colleagues [7] proposed the "transfer-beam structure model" and studied the relationship between hydraulic support and surrounding rock based on the given deformation and limit-deformation conditions. Wang and colleagues [8-9] study the process of roof stratum breakdown instability and dynamic evolution of hydraulic support load, putting forward the "stiffnessstrength-stability coupling model" between hydraulic support and surrounding rock, which provides an approach for dynamic analysis and prediction of hydraulic support load in longwall mining face. Some scholars have studied the evolution mechanism of coal and rock dynamics in the process of coal mining [10-13], revealed the mechanism of dynamic disaster occurrence, proposed the prevention and control idea based on source separation and classification, and developed supporting equipment which provided theoretical, technical and equipment support for dynamic disaster prevention and control. 
The above research results mainly studied the deformation, failure, instability and disaster occurred mechanism of roof strata, so as to predict and early warning the roof disaster. Due to the limitation of basic mechanics, fracture theory, geological exploration technology and other related basic theories and technology development, it is difficult to obtain the accurate theoretical solution of roof fracture instability and disaster occurrence mechanism.

With the development and progress of intelligent perception and network transmission technology, the electrohydraulic control system can realize the real-time monitoring of the pressure, posture and other information of the hydraulic support in the whole longwall mining face. The technologies of big data analysis and data modeling provide a new technical way for roof strata control, disaster prediction and early warning. The National Institute of Occupational Safety and Health in American has developed a hydraulic support monitoring and evaluation system [14], which realized the monitoring and early warning of hydraulic support state parameters, such as column leakage, insufficient initial support force and uneven column force. Sandford and Conover in Australia developed the GeoGuard System [15], which realized the prediction of weighting with thick hard sandstone roof strata. Trueman et al. [16-18] developed the Longwall Visual Analysis (LVA) system, extracted the time weighted working resistance of hydraulic support, initial support force, opening times of safety valve and other parameters, studied the influence of buried depth, longwall face width and other factors on the interacted relationship between hydraulic support and surrounding rock. University of Alabama developed Strata Control and Monitoring System of fully mechanized mining face to realize the real-time monitoring and statistical analysis of the hydraulic support load, and predict the periodic weighting of the mining face [19]. Scholars in China put forward the disaster prediction and early warning strategy based on multi-source information monitoring of the longwall face [20-24], and developed the intelligent prediction and early warning platform of roof disaster based on big data. The supporting technology and equipment, and the intelligent prediction and early warning technology of roof disaster based on perceptual information is explored.

The existing roof disaster monitoring and early warning technology mainly monitors the column pressure of hydraulic support [25-26], and carries out statistical analysis on the initial support force, the resistance forces at the end of support cycle and weighted working resistance of the column, so as to obtain the dynamic load coefficient and weighting step of the roof. There are the shortcomings as following: (1) It is difficult to fully reflect the support status of hydraulic support only by monitoring the column pressure (Whether there is poor condition of hydraulic support such as head up and head down); (2) The monitoring data types of hydraulic support are few, and the data dimension is low, so it is difficult to carry out deep data mining; (3) The traditional load data analysis method only carries on the statistical analysis of the data, the interpretability of the results is poor; (4) The general AI algorithm cannot be directly applied to the analysis and processing of support load data, which makes it difficult to realize the prediction and early warning of roof disaster.

In view of the above problems, this paper analyzes the current situation and main influencing factors of coal mine roof accidents in China. The monitoring information characteristic parameters of roof disaster were put forward based on the change of support load and posture. The feasibility and application of mathematical statistics method and big data modeling method were discussed applying to roof disaster prediction and early warning of longwall mining face. The technical architecture of the roof disaster intelligent prediction platform was build. The data modeling technology and the roof disaster prevention technology were tried to integrate and provided new methods for roof disaster prediction.

\section{Characteristic parameters of roof disaster}

\subsection{Current situation of roof disasters in China}

In recent years, the safety situation of coal mines in China has improved dramatically. In 2019, there were 316 people died for 170 accidents in coal mines, and the death rate per million tons was 0.083 [27]. Compared with 2000, the number of roof accidents and the number of deaths have decreased. The proportion of roof accidents and deaths decreased by $19.33 \%$ and $13.02 \%$, respectively. The distribution of the number of occurrences and deaths of different accidents types in Chinese coal mines is shown in Figure 1.

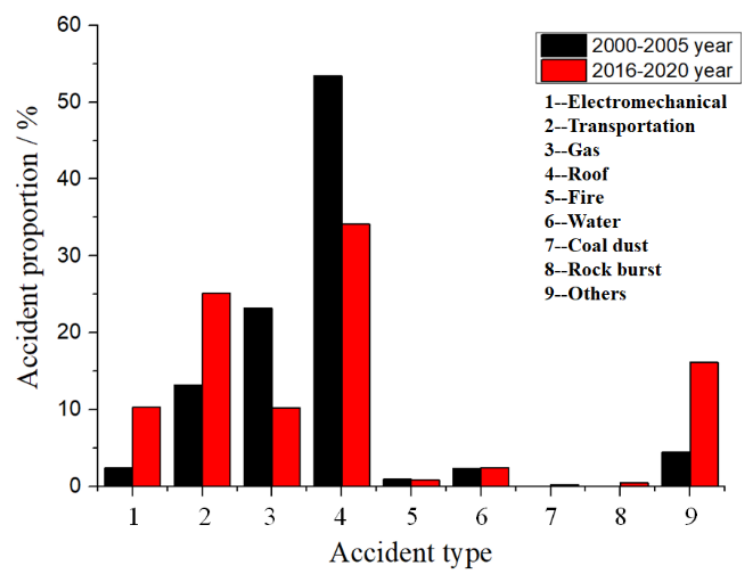

a. Changes in the number of coal mine safety accidents 


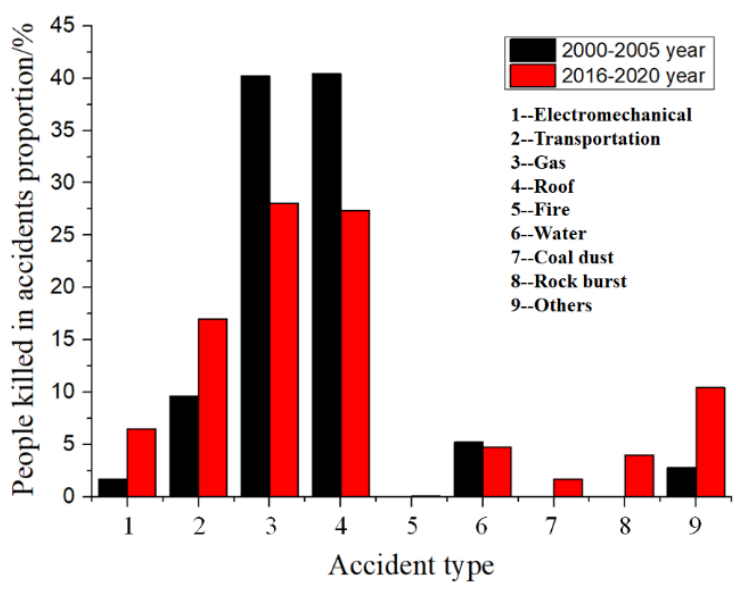

b. Changes in the death toll of coal mine safety accidents

Fig.1 Distribution of coal mine safety accidents in China

Although the number of roof accidents and the number of deaths have dropped significantly, the overall proportion is still high, which means roof accidents are still the main safety accidents in coal mines. The roof accidents in the longwall face are mainly caused by the failure of the hydraulic support to the roof, which is mainly manifested in roof leakage, coal wall spalling, and support crushing and so on. The support parameters, support state and adaptability to surrounding rock fracture and instability of hydraulic support are the main factors affecting the safety production of the mining face.

Restricted by the development of geological exploration technology and stress sensing technology, it is difficult to directly detect the stress distribution and fracture structure of the overlying strata in the longwall face. The fracture process of overlying strata can only be inferred according to the changes of the support load and posture. Therefore, the data of support load and posture is not only the basis of judging the surrounding rock control effect of longwall face, but also an important basis for prediction and early warning of roof disaster.

\subsection{Monitoring information of characteristic parameters}

With the advance of the longwall face, the hydraulic support continuously experiences the cycle operation of lowering, moving and lifting. The hydraulic support load presents the regular unloading, rapid pressurization, approximate constant pressure and other cyclic loading and unloading characteristics. The support load and supporting effect are not only affected by the roof fracture structure, but also restricted by the support position, support posture, advancing speed of the longwall face, manual operation and other factors. It is a kind of time series data showing cyclic dynamic changes with the advancement [28]. According to the influence factors of hydraulic support load and cycle change characteristics, this paper puts forward the monitoring information characteristic parameters of roof disaster based on the change of hydraulic support load and posture, as shown in Figure 2.

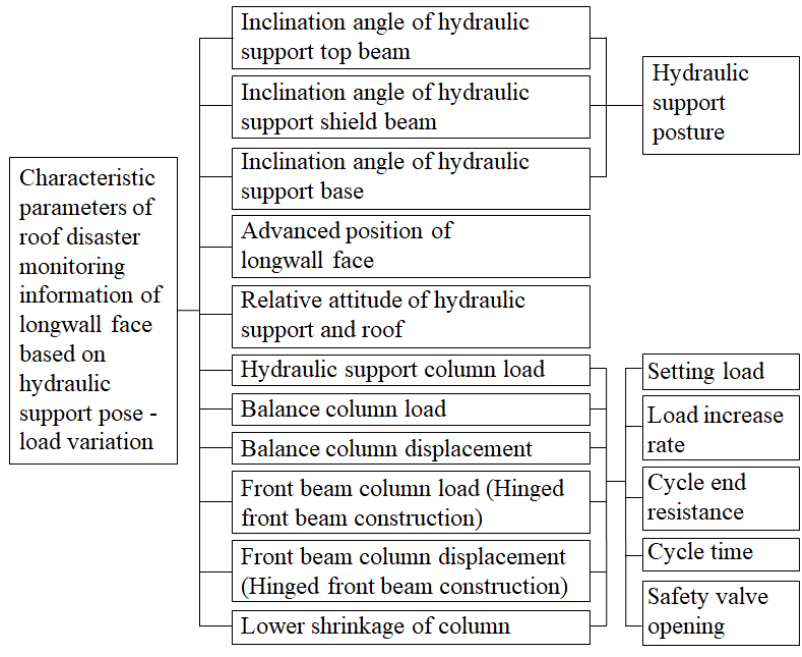

Fig.2 Monitoring information characteristic parameters of longwall face roof disaster

Monitoring the inclination of top beam, shield beam and base of the hydraulic support, the support posture can be obtained. Combined with the relative posture of the support and the roof and floor strata, the longwall face position and other information, the supporting state can be obtained. Through monitoring the column pressure, balance jack force (shield support), front beam jack force (hinged front beam structure support), side protection jack force, balance Jack stroke, front beam jack stroke, side protection jack stroke, column shrinkage, column shrinkage speed of the hydraulic support, the initial support force, resistance increasing rate, cycle end resistance, circulation speed, safety valve opening of the hydraulic support can be obtained. According to the support posture, load and other related parameters of the support, the posture-load decoupling calculation can be carried out, and the correlation model of the posture and load of the support is established. Because the support posture and load are not corresponding relationship, the posture-load database of the hydraulic support can be established through a large number of monitoring information, and the mapping model of the support posture and load can be established using the data analysis method, which provides data support for the prediction of the support state, the evaluation of the surrounding rock control effect and the prediction of roof disaster.

\section{General methodology}

\subsection{Engineering background}

The hydraulic support load not only has the cyclic variation characteristics, but also is affected by the time. It is a kind of time series data of cyclic variation. Due to the limitation of monitoring technology, production cost and other related factors, the column pressure of the hydraulic support is mainly monitored. The support posture, column shrinkage, jack stroke and other relevant information (some characteristic parameters in Figure 2) have not been fully monitored, which brings difficulties to the roof disaster prediction of the longwall face. Based on the column pressure monitoring data of 54\# hydraulic support in the middle of 30112 longwall face of Yanghuopan 
coal mine in Shaanxi Province, the support load is analyzed by data modeling method, which provides the basis for roof disaster prediction.

30112 longwall mining face is mined in $3 \#$ coal seam. The average thickness and buried depth of coal seam is $2.2 \mathrm{~m}$ and $120 \mathrm{~m}$, respectively. The length of mining face is $240 \mathrm{~m}$, the dip angle of coal seam is $1 \sim 2^{\circ}$. This mining face adopts
ZY7200/17/30D hydraulic support, the center distance is $1.5 \mathrm{~m}$, opening pressure of column safety valve is $41.9 \mathrm{MPa}$, and the support strength is about $0.95 \mathrm{MPa}$. The support pressure is collected by equal time interval $(10 \mathrm{~min})$, and the monitoring data of continuous 4 days are intercepted for analysis. The original data is shown in Figure 3.

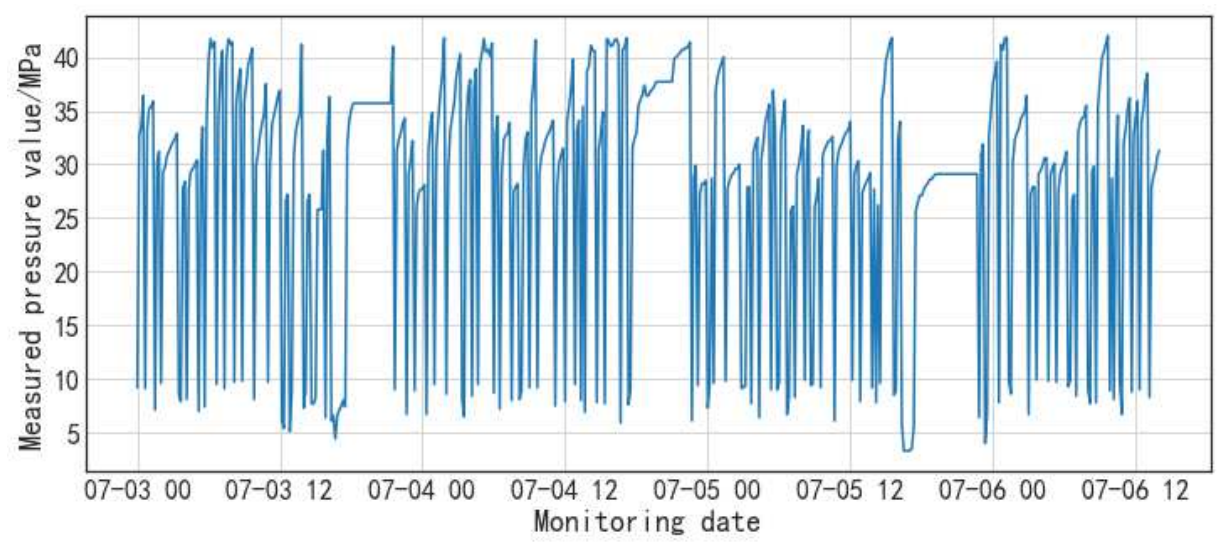

Fig.3 Monitoring load of hydraulic support

\subsection{Feature decomposition of hydraulic support load data}

Since the hydraulic support load has the cyclic variation characteristics, the original load data is decomposed into trend item, cycle period item and residual item by feature decomposition method. The result of original data decomposition is shown in Figure 4.

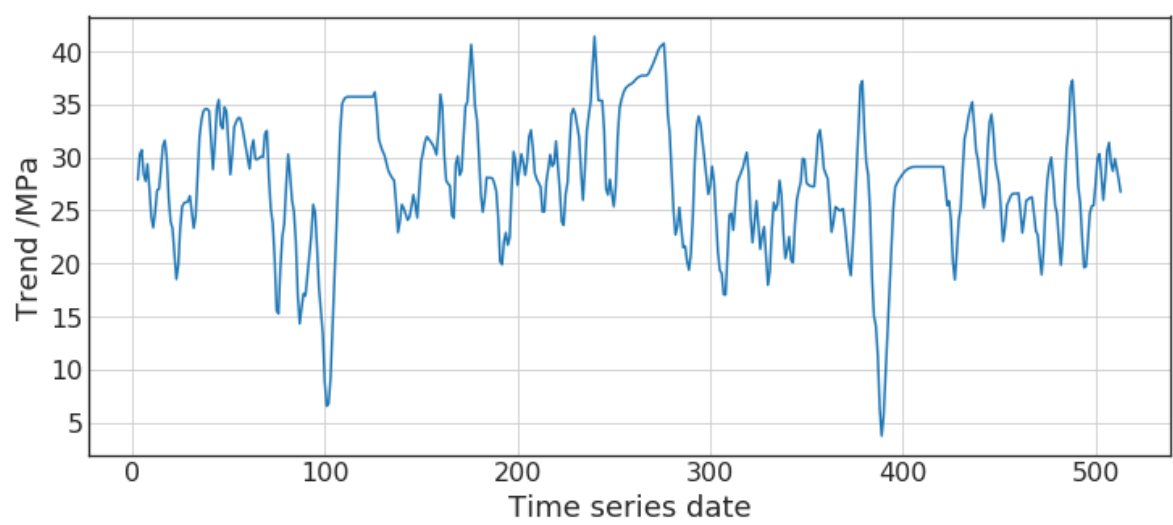

a. Trend item of support load change

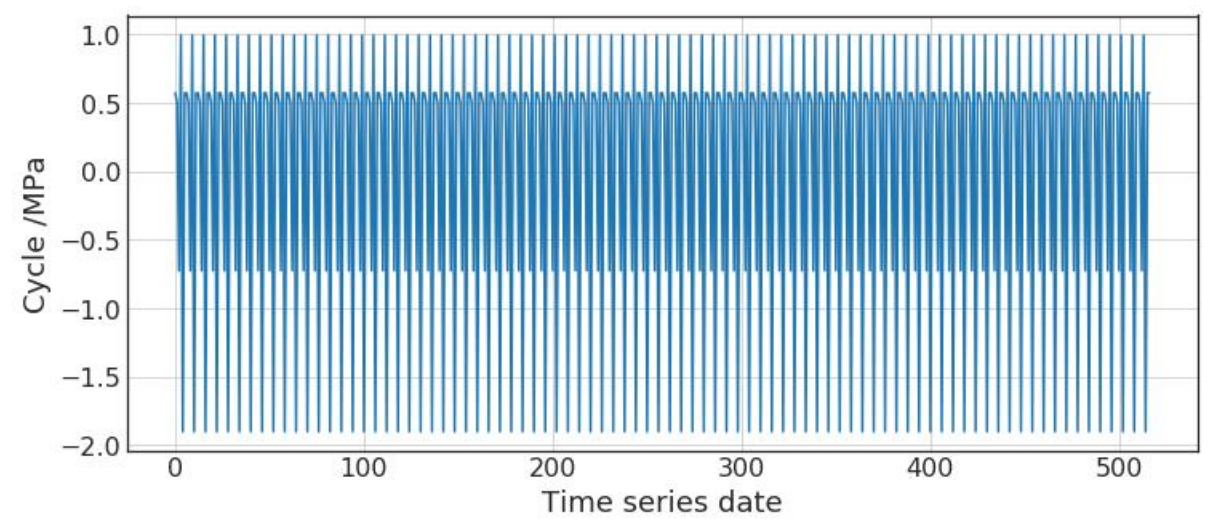

b. Cycle period item of support load change 


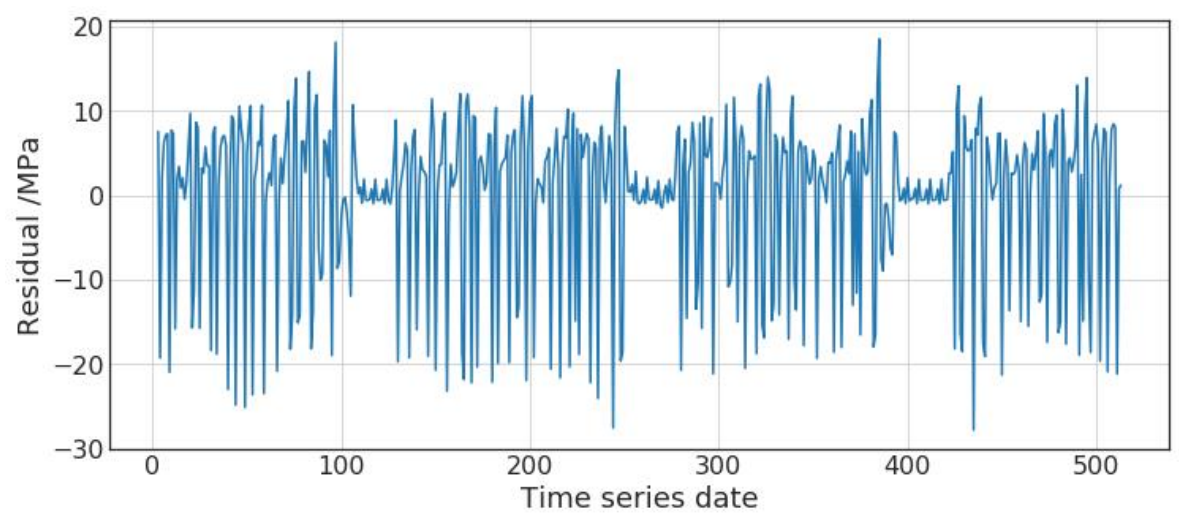

c. Residual item of support load change

Fig.4 Feature decomposition of monitoring support load

Analyzing the characteristic decomposition of the original monitoring data, it is found that the sampling density of the hydraulic support in different cycle periods is quite different due to the equal time interval sampling. For example, the maintenance team did not carry out cutting operation, and the support load did not change periodically, but a large number of data were collected, resulting in a large deviation between the characteristic decomposition results and the real situation. The trend item does not show obvious change at the end of decomposition, and there is a big data fluctuation before and after the maintenance operation. Although the extracted cycle item is very regular, it shows a trend of first decline, then rise, and then decline, which is also quite different from the cycle change of hydraulic support (increasing resistance, constant resistance, reducing resistance). The extracted residual item fluctuates violently and has a large asymmetry. Therefore, it is difficult to separate good feature information from the original load data directly by feature decomposition.

In order to avoid the difference of data density in different cycle of hydraulic support caused by equal time interval sampling, the original monitoring data are preprocessed to make the data density of each cycle the same, and the minimum load, initial load, maximum load and final load are retained. Only these four data are retained in each support cycle. The preprocessed result is shown in Figure 5.

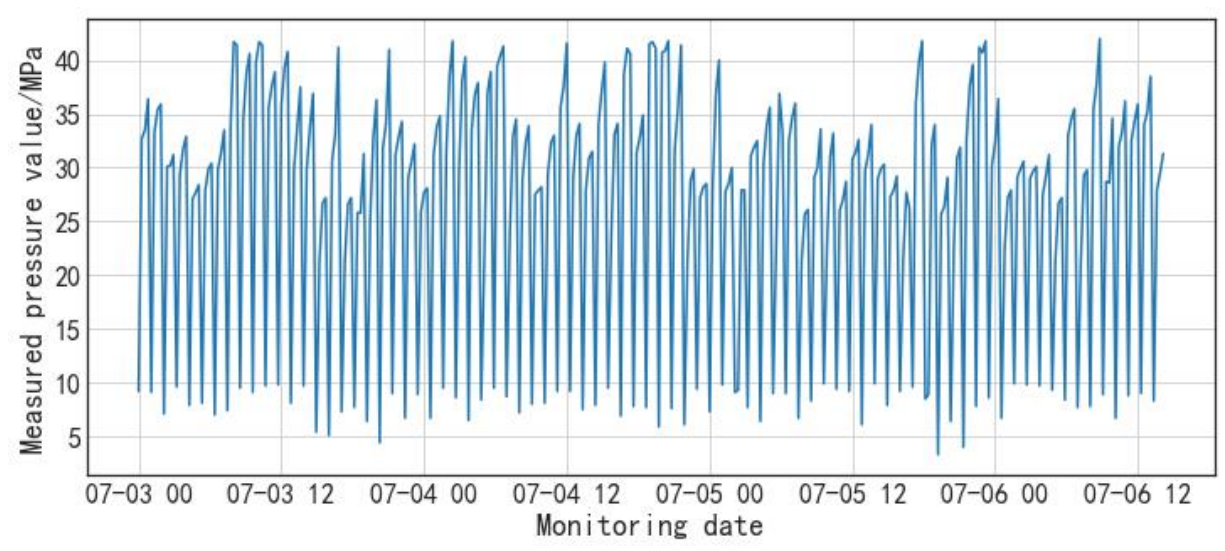

Fig.5 Preprocessed load data of support

It can be seen from Figure 5 that each support cycle of the preprocessed load data has the same data density, but the regularity of the data change is not obvious, so it is difficult to obtain the periodic weighting characteristics of the roof. Therefore, the characteristic decomposition of the preprocessed load data is carried out, and the result is shown in Figure 6. 


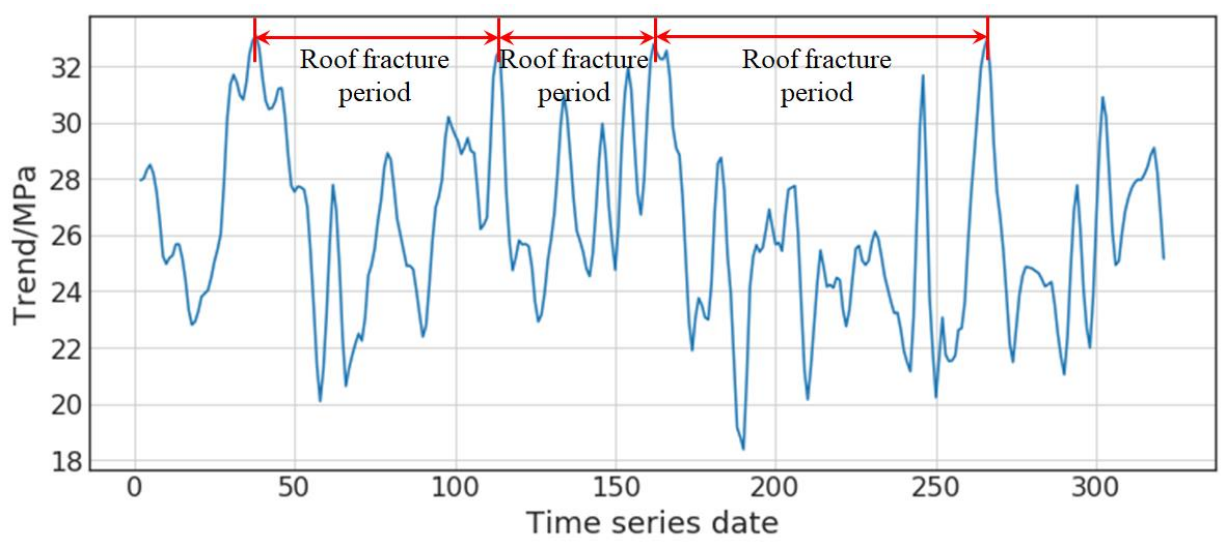

a. Trend item of support load change

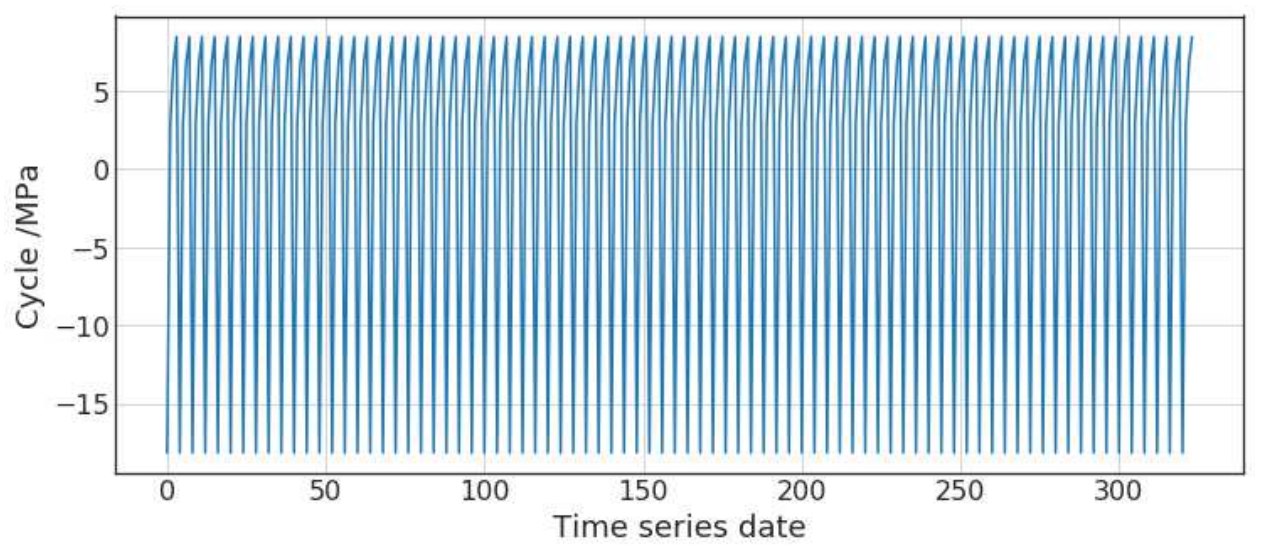

b. Cycle period item of support load change

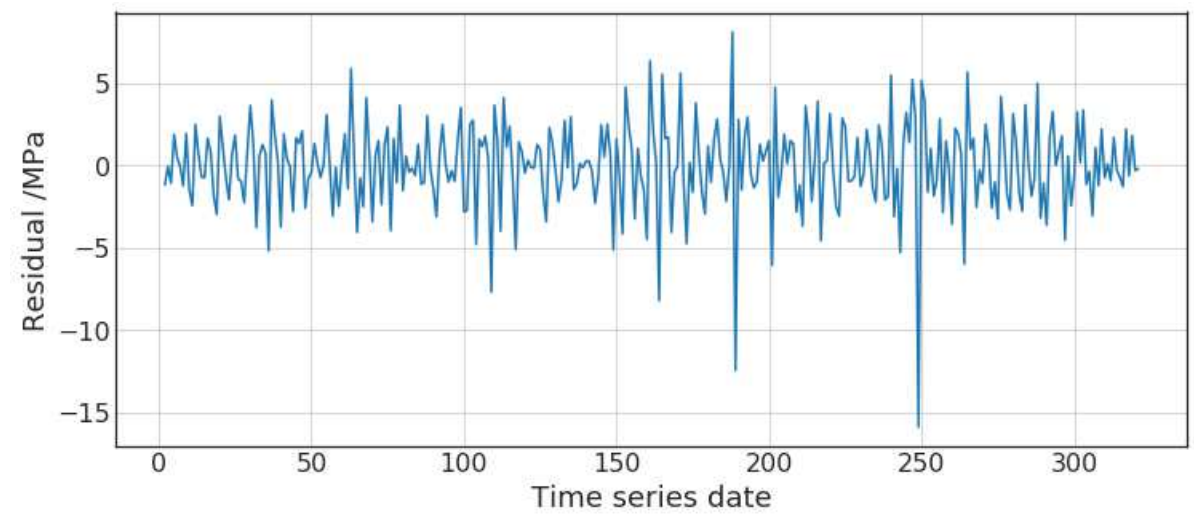

c. Residual item of support load change

Fig.6 Feature decomposition of preprocessed monitoring support load

Analyzing the feature decomposition result of preprocessed data, it is found that the separated trend item can better characterize the periodic fracture characteristics of the roof strata. There are three complete periodic weighting records in the intercepted data, which is basically consistent with the actual monitoring situation of the longwall face. The cyclic item shows regular characteristics of increasing resistance, peak value and reducing resistance, which is similar to the cyclic variation characteristics of support load; the residual item value is small, and basically fluctuates around zero, which conforms to the white noise characteristics.
Based on the above analysis results and the statistical theory and preprocessed monitoring load data of the hydraulic support, the cycle item of the support load and the roof periodic weighting can be well decomposed. On this basis, the load data modeling can be carried out by using machine learning, depth learning and other methods, and the historical monitoring data can be used to model the hydraulic support load. Based on the prediction results, the roof weighting can be deduced and the roof disaster can be predicted.

\section{Support load data modeling and prediction}

At present, time series data can be modeled and analyzed by using exponential smoothing method, autoregressive model, 
machine learning, deep learning and other algorithms [2931]. Using the historical monitoring load, it can predict the load of a subsequent single monitoring point, the subsequent support cycle and the fracture cycle of roof strata. As the predicted range increases, the difficulty of prediction increases and accuracy decreases.

\subsection{Single point prediction support load}

Because the acquisition frequency of support column load is relatively high, it is easy to use historical data to predict the next acquisition value (single point prediction), and the accuracy is great. The support load data is affected by many factors, while mainly affected by the statistical value and trend item of historical monitoring data. Therefore, the double exponential smoothing algorithm is used for single point prediction of support load [32], as follows:

$$
\left\{\begin{array}{c}
l_{t}=\alpha y_{t}+(1-\alpha)\left(l_{t-1}+b_{t-1}\right) \\
b_{t}=\beta\left(l_{t}-l_{t-1}\right)+(1-\beta) b_{t-1} \\
\hat{y}_{t+1}=l_{t}+b_{x}
\end{array}\right.
$$

Where, $y_{t}$ is the monitoring value at the current time, $\hat{y}_{t+1}$ is the predicted value at the next time, $l_{t}$ is the expected value of monitoring data at the current time; $l_{t-1}$ is the expected value of monitoring data at the previous moment; $b_{t}$ is the trend item of monitoring data at the current time; $b_{t-1}$ is the trend item of monitoring data at the previous moment; $\alpha$ is the exponential smoothing factor; $\beta$ is the exponential smoothing weight.

According to the monitoring results of hydraulic support load in 30112 longwall face, the double exponential smoothing algorithm is used to predict the load monitoring data of support. By optimizing the exponential smoothing factor $(\alpha)$ and exponential smoothing weight factor $(\beta), \alpha=0.95$ and $\beta=$ 0.05 are determined. The single point prediction is shown in Figure

7.

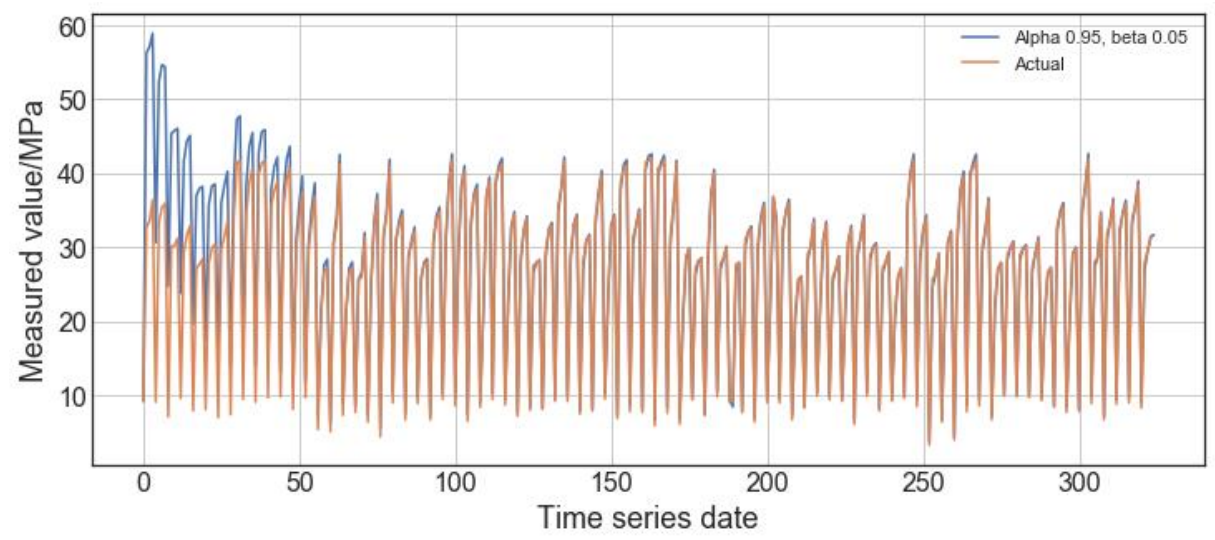

Fig.7 Support load prediction based on the double exponential smoothing algorithm

Through the analysis of Figure 7, it is found that due to the small number of monitoring data in the early stage, the deviation degree of the predicted value is large. With the continuous accumulation of monitoring data, the predicted value is basically consistent with the measured value (approximately coincident), indicating that the single point prediction effect is better.

Predicting the peak load of hydraulic support, the possibility of roof disaster can be inferred. In addition, a simple sliding window model can predict the peak load, as shown in Figure 8.

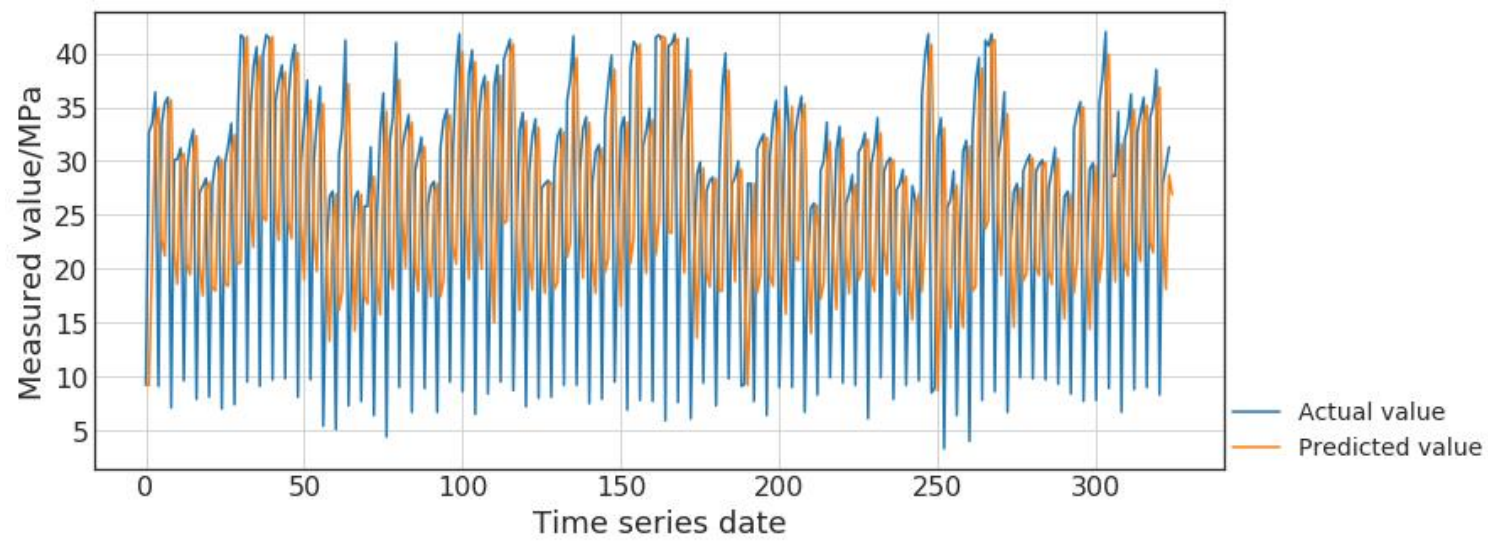

Fig.8 Support load prediction based on the sliding window model

In addition, the long short-term memory (LSTM) model, support vector regression (SVR) and autoregressive (AR) model are used to predict the column load of support. Without deep adjustment, the overall good prediction effect is achieved. Root mean square error (RMSE) and mean absolute error 
(MAE) are used to compare. It is found that the prediction effect of AR model is relatively good, as shown in Table 1.

Table 1 Prediction effect of different algorithms

\begin{tabular}{ccccc}
\hline Algorithm & RMSE & MAE & $\begin{array}{c}\text { Accuracy within } \\
5 \%\end{array}$ & $\begin{array}{c}\text { Accuracy within } \\
10 \%\end{array}$ \\
\hline LSTM & 0.3551 & 0.1866 & $36.22 \%$ & $52.47 \%$ \\
SVR & 2.0164 & 0.9223 & $31.44 \%$ & $46.52 \%$ \\
AR & 0.1422 & 0.1012 & $61.32 \%$ & $74.77 \%$ \\
\hline
\end{tabular}

\subsection{Load prediction for one support cycle}

Through the feature decomposition of the support load data, it can be seen that the load data has obvious trend and cycle characteristics, and the feature dimension of the data is very low, mainly contains the column load data. The autoregressive (AR) model has achieved good prediction effect without deep adjustment. Therefore, the autoregressive integrated moving average (ARIMA) model is used to predict the support load in one support cycle.

ARIMA model requires that the data must be stationary, which means the mean and variance of the data do not change with time. The augmented dickey-fuller (ADF) is used to test the stability of the support load, and the autocorrelation function (ACF) and partial autocorrelation function (PACF) are used to analyze the stationarity and autocorrelation of the data. Although the preprocessed data meet the test results, there is an obvious lag point between the autocorrelation coefficient and the partial autocorrelation coefficient, as shown in Figure 9. After the fourth order ( $d=$ 4) difference calculation of the original monitoring data, the data has better stability. The comparison of ADF results before and after the difference is shown in Table 2. The results of autocorrelation comparative analysis are shown in Figure 9. The shaded area covers the confidence interval.

Table 2 Test result of stability of load data

\begin{tabular}{cccccc}
\hline Item & $\begin{array}{c}\text { Inspection } \\
\text { findings of } \\
\mathrm{T}\end{array}$ & P value & $\begin{array}{c}99 \% \\
\text { confidenc } \\
\text { e interval } \\
\text { test }\end{array}$ & $\begin{array}{c}95 \% \\
\text { confidenc } \\
\text { e interval } \\
\text { test }\end{array}$ & $\begin{array}{c}90 \% \\
\text { confidence } \\
\text { interval test }\end{array}$ \\
\hline Before & & & & & \\
diff & -3.523 & 0.0074 & -3.4519 & -2.871 & -2.5718 \\
After & & & & & \\
diff & -7.945 & $3.2 \mathrm{e}-12$ & -3.4541 & -2.872 & -2.5731 \\
\hline
\end{tabular}

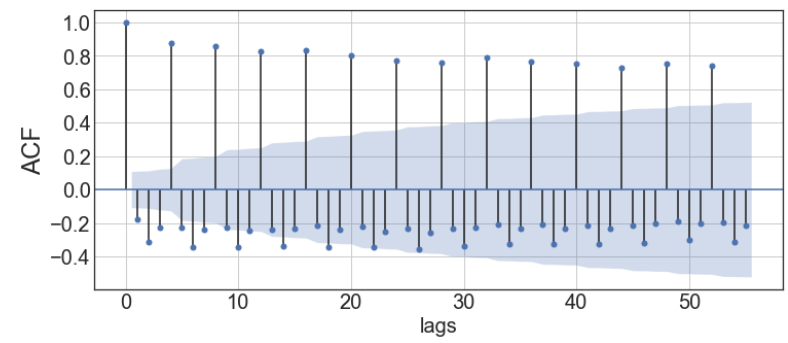

a. Autocorrelation graph of original monitoring data (ACF)

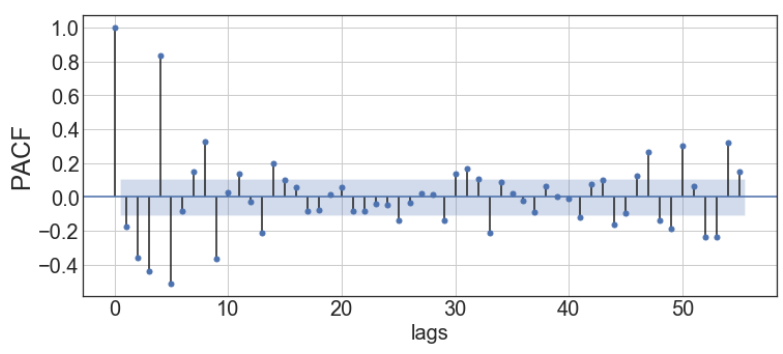

b. Partial autocorrelation graph of original monitoring data (PACF)

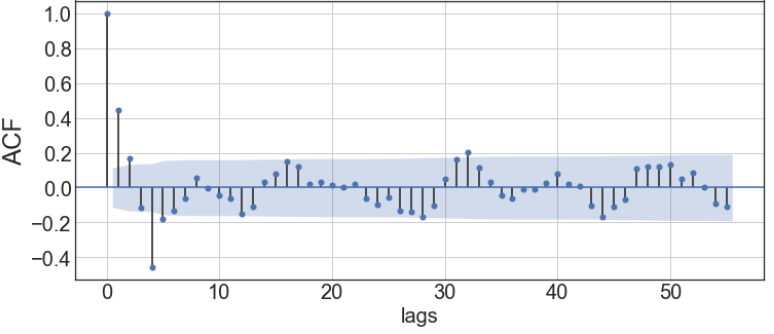

c. Autocorrelation graph after difference calculation (ACF)

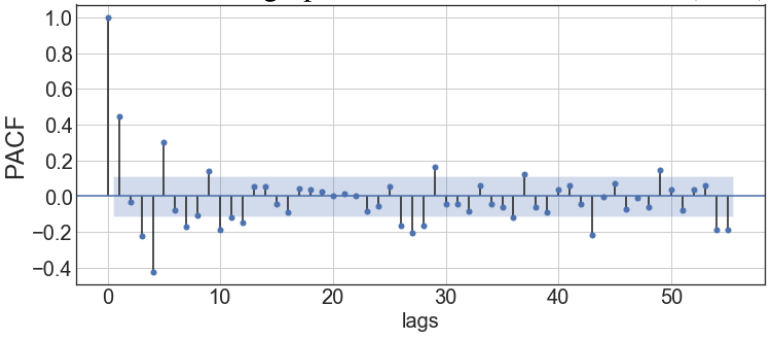

d. Partial autocorrelation graph after difference calculation (PACF)

Fig.9 Autocorrelation graph and partial autocorrelation graph of monitoring data before and after differential calculation

Through the analysis of the above figure, it is found that after the fourth order difference calculation, the phenomenon that the autocorrelation coefficient and the partial autocorrelation coefficient of the monitoring data have a lagging point has been improved. In order to determine the values of autoregressive item (p) and sliding average item (q), a grid search method was used to search and calculate the data models with the range of autoregressive item $(2 \leq p \leq 8)$ and moving average item $(2 \leq \mathrm{q} \leq 8)$. A total of 36 groups of data models were selected to optimize the model parameters by using the Akaike Information Criterion (AIC) and Bayesian Information Criterion (BIC). When $\mathrm{p}=5$ and $\mathrm{q}=4$, the AIC and BIC values of the model are the minimum at the same time $(\mathrm{AIC}=1706.01, \mathrm{BIC}=1743.15)$. Therefore, the model parameters are determined as $P=5, d=4, q=4$. At this time, the residual value of the model basically presents the characteristics of white noise, as shown in Figure 10.

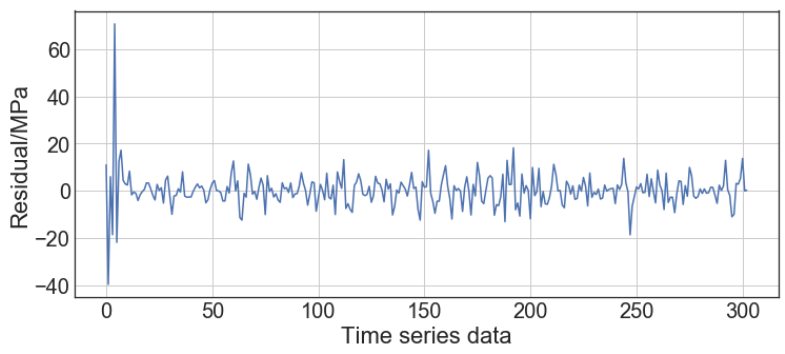

Fig.10 Residual value of model optimization 
The optimized data model is used to predict the support load in one support cycle, as shown in Figure 11. Through the analysis of the prediction results, the fitting effect of the model on the hydraulic support load is good as a whole, and the peak value and variation law of the next support cycle are predicted, but the predicted results still have a certain deviation from the measured results.

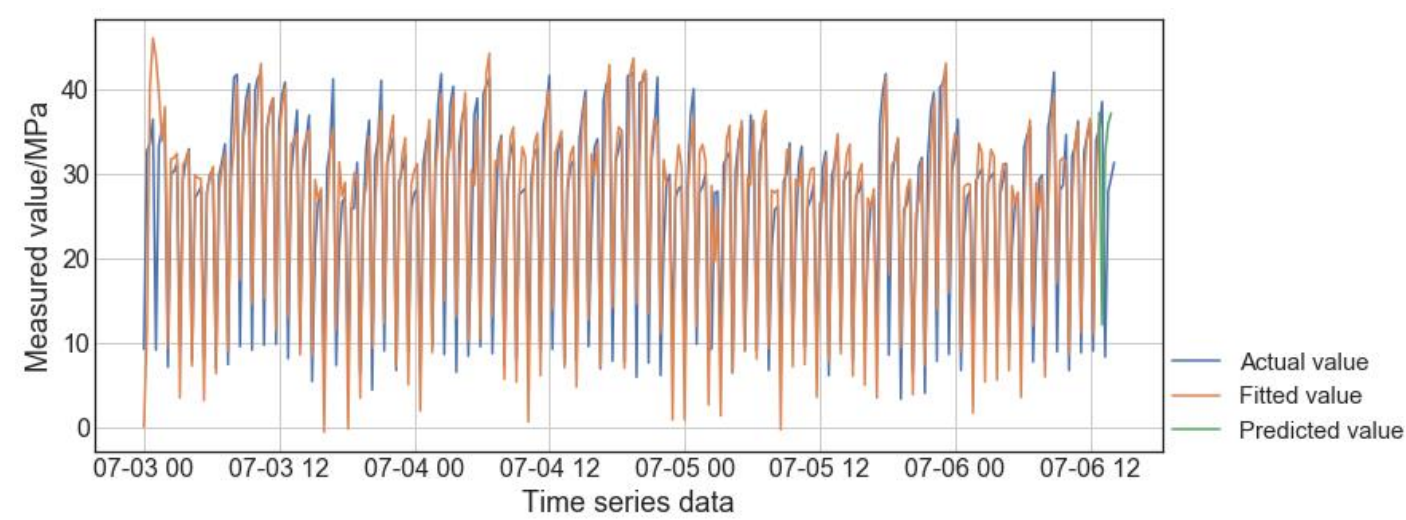

a. Overall fitting result

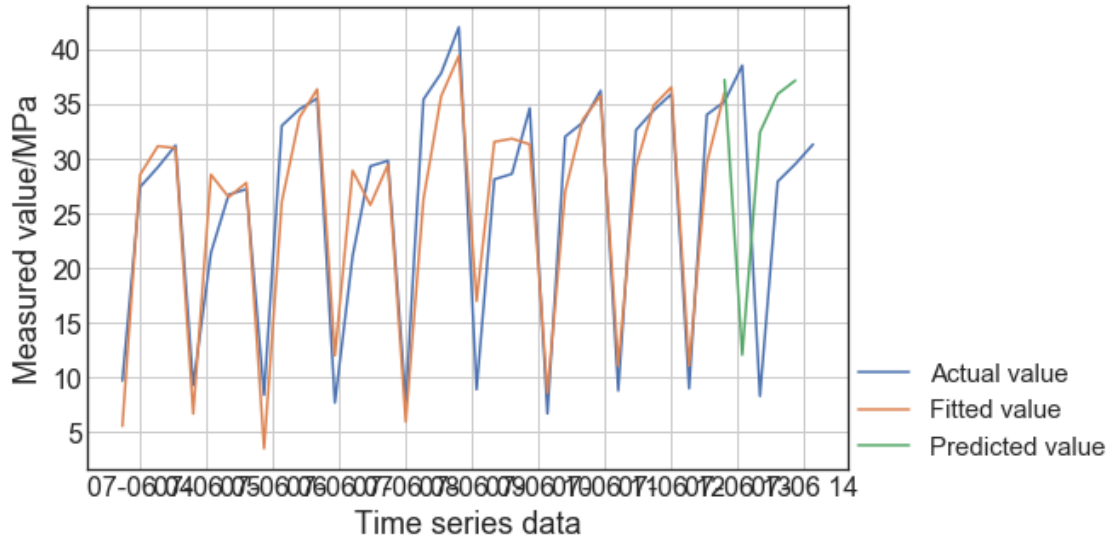

b. Local fitting result

Fig.11 ARIMA model fitting result

Because the support load data has obvious cycle characteristics, in order to improve the prediction accuracy, SARIMA model with cycle item is used to predict the support load. First, the data is differentiated for a cycle period, and then the first order difference is performed to improve the data stability. The grid search method is also used to search and calculate the value range of autoregressive item $(2 \leq \mathrm{p} \leq 6)$, moving average term $(2 \leq \mathrm{q}$ $\leq 6)$, cyclic autoregressive term $(2 \leq \mathrm{P} \leq 4)$ and cyclic moving average $(2 \leq \mathrm{Q} \leq 4)$. A total of 64 data models are selected, Akaike Information Criterion (AIC) and Bayesian Information Criterion (BIC) are used to optimize the parameters of the model, and the optimal parameters are determined as $\mathrm{p}=3, \mathrm{q}=$ $3, \mathrm{P}=2, \mathrm{Q}=3$. The optimized data model is used to predict the support load of one support cycle. The fitting and prediction results are shown in Figure 12.

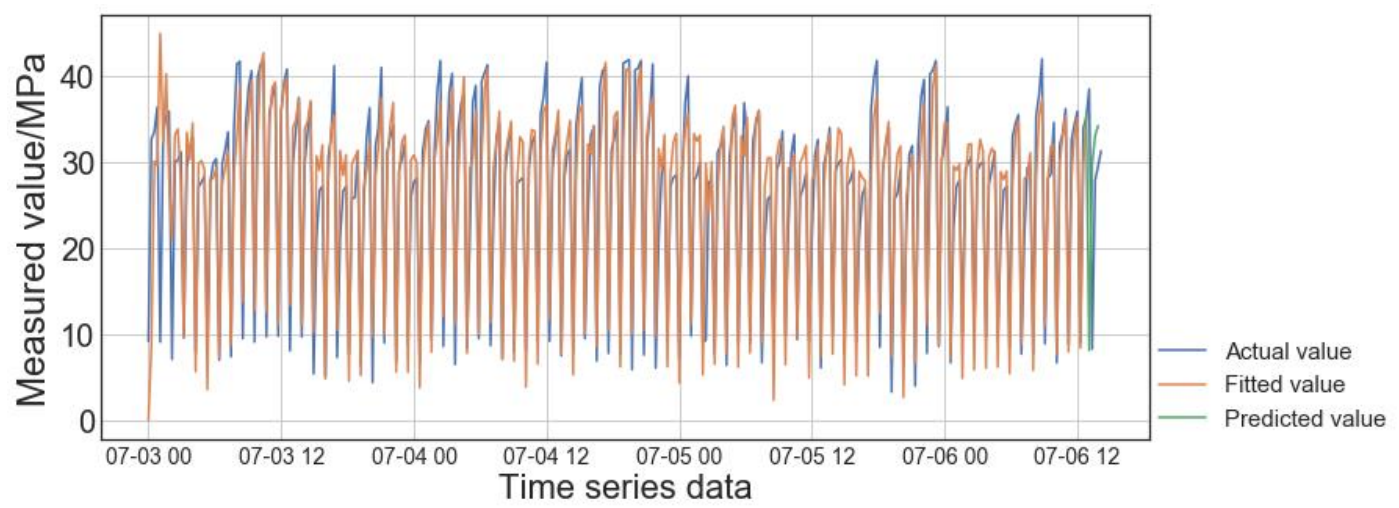

a. Overall fitting result 


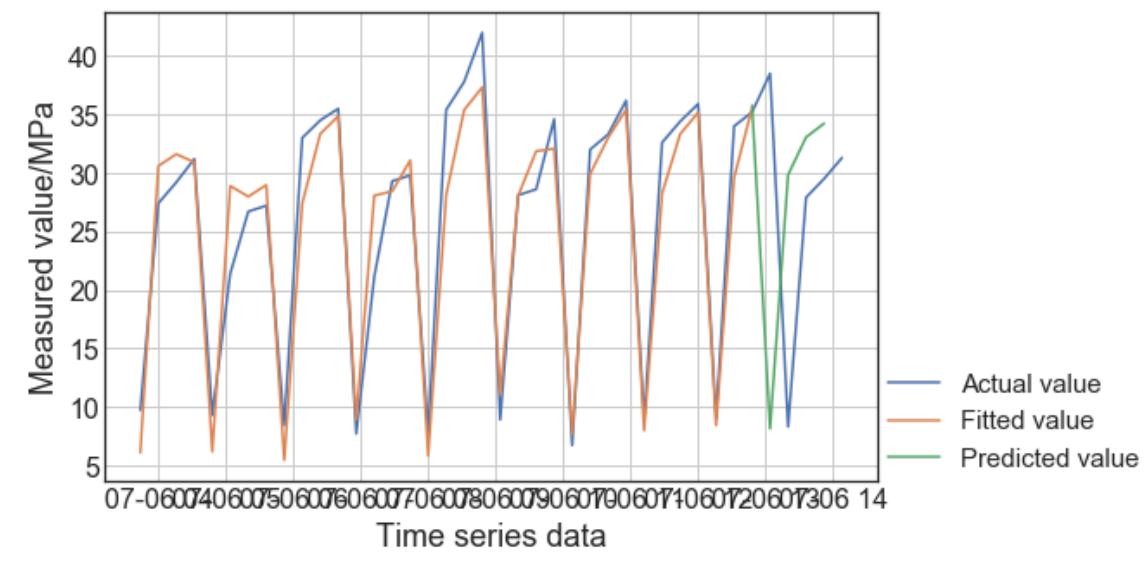

b. Local fitting result

Fig.12 SARIMA model fitting result

\subsection{Load prediction of hydraulic support for one roof} fracture cycle

Since the roof strata presents the characteristics of periodic fracture, and the fracture cycle in different areas of the longwall mining face is different. It is necessary to predict the hydraulic support load in a fracture cycle, so as to provide sufficient time for the prevention and control of roof disasters. The ARIMA model and SARIMA model are used to predict the support load in multiple cycles, as shown in Figure 13.

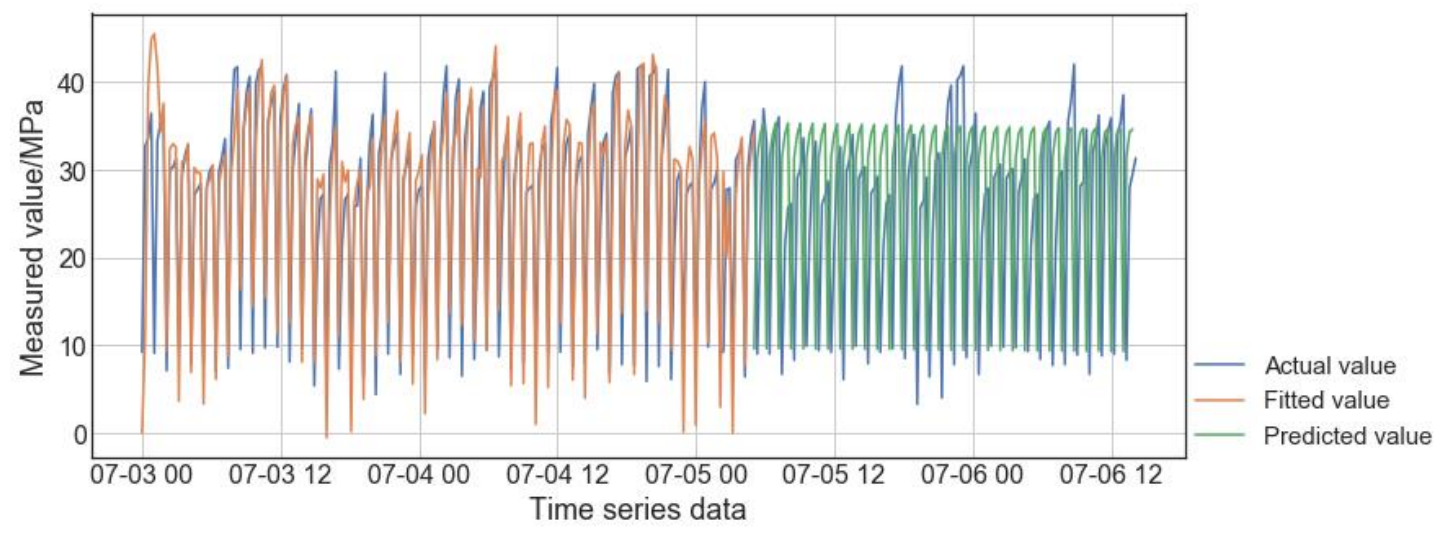

a. ARIMA model

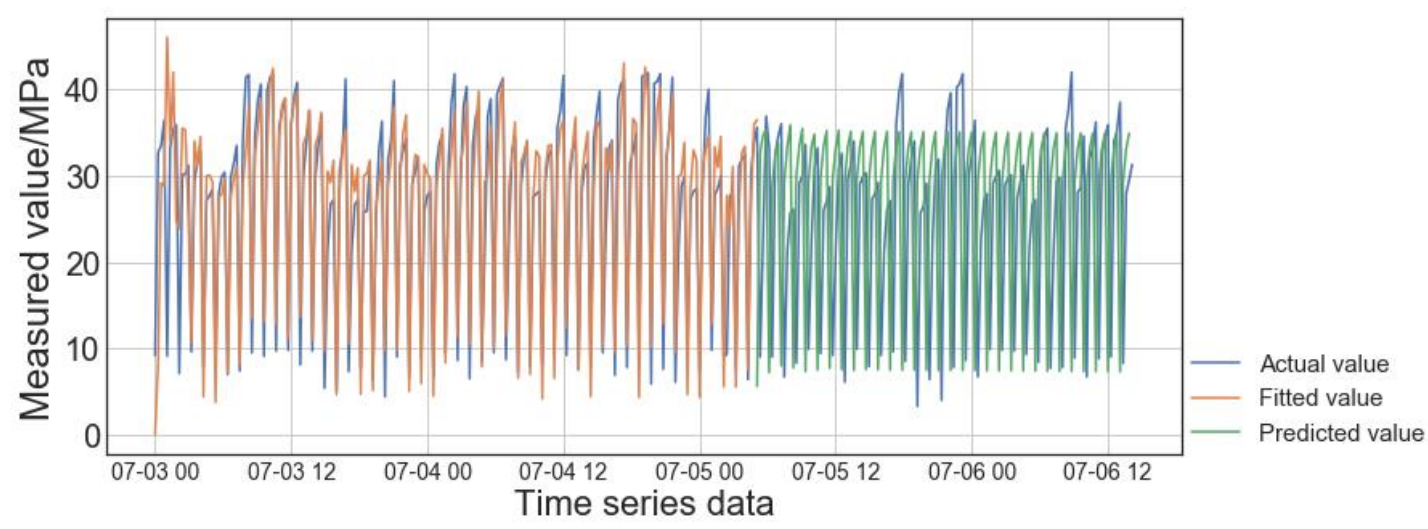

b. SARIMA model

Fig.13 Different models to predict the support load in multiple cycles

It can be seen from the above figure that because the support load in different circulation support processes have little change. ARIMA model and SARIMA model can only capture the load of the following 1-2 cycles, while the subsequent predicted value is quite different from the real value, which means neither of the two models can accurately predict the support load in a roof fracture cycle.

\section{Discussion}

5.1 Comparative analysis of data model prediction effect

Because of the high frequency of support load acquisition, 
the single point prediction of hydraulic support load is realized by using the above algorithms, and the overall prediction results are good. However, the single point prediction of the next acquisition is not of great engineering significance. Taking 30112 longwall mining face as an example, the data acquisition frequency is 10 minutes. Even if it can accurately predict the next acquisition and infer the impending roof disaster according to the predicted results, the time is too short for disaster prevention. Therefore, it is necessary to predict the load change at least one support cycle in advance.

Comparing the load prediction results of ARIMA model and SARIMA model for one support cycle, the result of SARIMA model is closer to the measured data. The root mean square error (RMSE) was used to compare the fitting effects of the two models [33]:

$$
R M S E=\sqrt{\frac{\sum_{i=1}^{n}\left(X_{o b s, i}-X_{\text {model }, i}\right)^{2}}{n}}
$$

Where, $X_{o b s, i}$ is the monitoring value at time i, $X_{\text {model }, i}$ is the predicted value at time $i$.

The calculation result shows that the RMSE of SARIMA model is 4.34 , and that of ARIMA model is 4.76. SARIMA model is obviously better than ARIMA model. In addition, this paper uses three order exponential smoothing algorithm (Holt winters) and LSTM algorithm to predict the load of one support cycle. Although the predicted result has a certain deviation from the measured value, the overall prediction is also good. Because a cycle of cutting coal is about one hour in the high-intensity mining face of western mining area, it is still difficult to predict the support load in one support cycle for disaster prevention and treatment. It is better to predict the load in one fracture cycle of roof strata.

ARIMA model and SARIMA model are used to predict the load of hydraulic support in a fracture cycle. Although both models obtain the cyclic variation characteristics of hydraulic support, the prediction of peak value and variation law of hydraulic support load is poor. Root mean square error (RMSE) is used to compare the fitting effect of the two models. The RMSE value of ARIMA model is 5.62 The RMSE value of SARIMA model is 5.18. Neither of the two models can predict the support load in one fracture cycle of roof strata. We also use LSTM algorithm and RNN algorithm to model and analyze the data, but the load prediction for one roof fracture cycle is not ideal.

\subsection{Discussion on prediction method for one roof fracture cycle}

At present, there are few related researches focused on prediction and early warning of roof disaster in longwall face, and scholars mainly focus on the stress field evolution characteristics and fracture structure of roof strata [34-36]. The studies focused on the roof disaster prediction using data model are less. The related algorithm results which can predict the support load with one fracture cycle have not been retrieved.

Based on the load prediction method of one support cycle of hydraulic support, a prediction method based on multiple data cutting and load template library of hydraulic support is proposed, which can predict the support load in one fracture cycle of roof. Firstly, according to the load characteristics (increasing resistance, constant resistance and reducing resistance) in one support cycle, the load data in the whole longwall face was cut, and the load of each cycle of hydraulic support was fitted by the above algorithm, and the similar fitting curve was classified into one class, and the support load template curve library of single cycle was established. Then, according to the variation law of peak load of each cycle, the fracture step of roof strata is determined, and the load template curve of hydraulic support in each fracture cycle is sorted, and the load change template library of hydraulic support based on the fracture cycle of roof strata is established, as shown in Figure 14. Finally, according to the existing monitoring data, the load curve of the subsequent cycle is predicted, and compared with the single support cycle in load template curve library, and the classification algorithm is used to determine the most likely change trend of the support load in a roof fracture cycle, so as to realize the prediction of hydraulic support load in a fracture cycle.

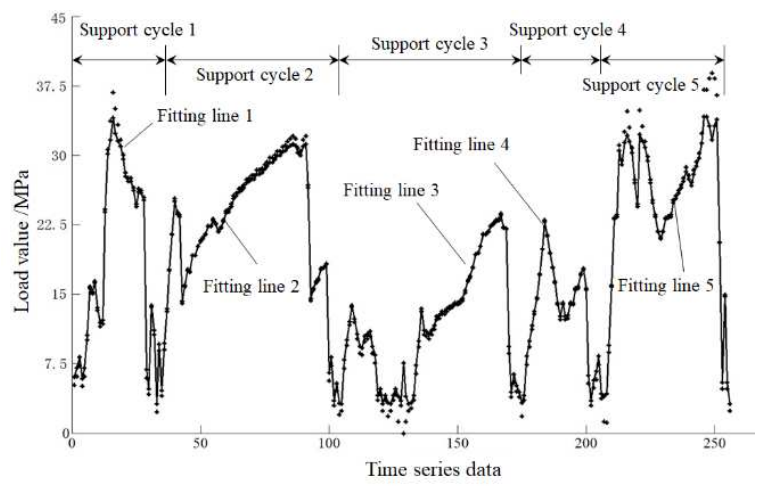

Fig.14 Sequence of support load template curves for one fracture cycle of roof strata

The above methods need to establish a fitting curve template library of cycle support load, a fitting curve template library of support load for a roof fracture cycle, which means it needs a large number of load data as samples for training. Based on the load data in some coal mines in Northern Shaanxi, we try to use the above method to predict the support load in one fracture cycle of roof strata, and obtain some meaningful results.

\subsection{Technical framework of roof disaster intelligent prediction platform}

Based on the monitoring information characteristic parameters of roof disaster and prediction method of support load, the technical framework of intelligent prediction platform for roof disaster is proposed in Figure 15. (Taking two column shield hydraulic support as an example) 


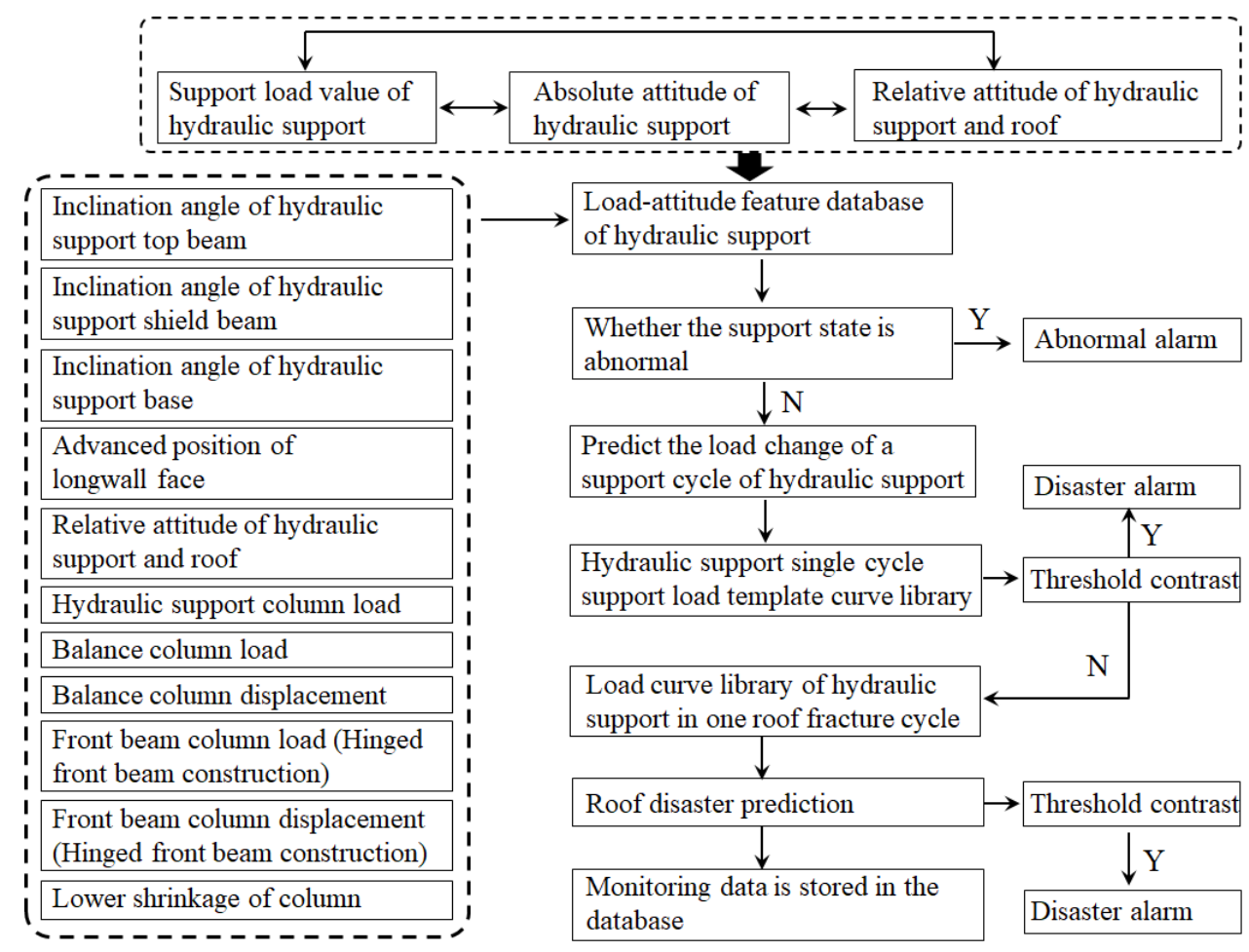

Fig.15 The technical framework of intelligent prediction platform for roof disaster

By mapping a large number of monitoring load data, absolute posture monitoring values and relative posture monitoring values of hydraulic support, the posture-load characteristic database of hydraulic support is established. The roof beam inclination angle, column pressure, column shrinkage and other related information monitored at the longwall mining face were put into the posture-load characteristic database of hydraulic support for comparison, and whether the support state was abnormal was judged. If there is any abnormality, alarm will be given, and the support load and posture will be adjusted manually. If there is no abnormality, based on the load prediction method of one support cycle, the load variation law of the next support cycle is predicted. The prediction are put into the load template curve library of single cycle support for comparison, and the load change template curve of hydraulic support is determined by classification algorithm, and compared with the occurrence threshold of roof disaster. If the predicted value exceeds the threshold of roof disaster, disaster alarm will be given. If not, the predicted single cycle support load template curve is put into a load curve template library of roof fracture cycle. The load variation law of hydraulic support in the next roof fracture cycle is predicted, and compared with the roof disaster threshold. If the predicted load exceeds the threshold of roof disaster, the disaster alarm will be given. When a hydraulic support cycle is completed, the monitoring data is stored in the single cycle support load template curve library. When the support load monitoring of a roof fracture cycle is completed, the load monitoring data of the whole cycle are stored in support load curve template library. Increasing the number of samples can improve the accuracy of roof disaster prediction.
Due to the space limitation, this paper does not discuss the establishment of posture-load characteristic database of hydraulic support and the determination of roof disaster threshold. In addition, if there is no predicted cycle support curve in the curve library of hydraulic support in the single cycle support load template, the floating range of predicted value is calculated by statistical principle. If the maximum floating value exceeds the threshold of roof disaster, the roof disaster alarm will be given.

\section{Conclusions}

(1) The bearing characteristics of hydraulic support, support posture, the relative posture between support and roof and floor, support state parameters are the main factors affecting the control effect of the roof. The monitoring information characteristic parameters of roof disaster based on the change of hydraulic support posture and load are obtained.

(2) The feature decomposition method can extract the variation trend and cycle term of hydraulic support load, and the sampling density between different cycle periods of hydraulic support has a great influence on the result of feature decomposition After equal density sampling of hydraulic support load data, the load change trend term after feature decomposition can better represent the periodic weighting characteristics of roof, and the change law of cycle term is basically consistent with the periodic characteristics of hydraulic support load.

(3) The single point prediction of various algorithms for hydraulic support load are all good, but the actual engineering significance of single point prediction of 
hydraulic support load is not great; ARIMA model and SARIMA model can predict the load in one support cycle, and SARIMA model has better prediction. Neither ARIMA model nor SARIMA model can predict the support load in one fracture cycle of roof strata.

(4) This paper proposes a hydraulic support load prediction method based on multiple data cutting and hydraulic support load template library. Through multiple data cutting, the template library of load fitting curve for single hydraulic support and one template library for load fitting curve of hydraulic support with roof fracture period are established. Then the classification algorithm is used to determine the most likely change trend of the hydraulic support load in a roof rock fracture cycle, so as to realize the prediction of the hydraulic support load in a roof fracture cycle.

(5) Based on the monitoring information characteristic parameters of roof disaster and hydraulic support load prediction method, the technical framework of roof disaster intelligent prediction platform is proposed, which can realize the prediction and early warning of roof disaster based on the monitoring load and posture parameters.

\section{Acknowledgments}

The study was supported by the National Natural Science Foundation of China (51674243, 52004124). The authors express their gratitude to the Yanghuopan Coal Mine for providing the field measurements and observations used in this work.

\section{References}

[1] Peng Syd S, Cheng Jingyi, Du Ffeng, et al. Underground ground control monitoring, interpretation, numerical modeling, and shield capacity design [J]. Journal of Mining Science and Technology, 2019, 29(1):79-85.

[2] Bai Qingsheng., Tu Shihao. A general review on longwall mining-induced fractures in near-face regions. Geofluids. 2019; (19): 1-22.

[3] Xie Jianlin., Xu Jialin. Effect of key stratum on the mining abutment pressure of a coal seam. Geosciences Journal. 2017; 21(2): 267-276.

[4] Qian M.G., Miao X.X., Xu J.L. Theoretical study of key stratum in ground control. Journal of China Coal Society. 1996; 21: 225-230. (In Chinese)

[5] Qian M.G., Xu J.L. Behaviors of strata movement in coal mining [J]. Journal of China Coal Society. 2019; 44(4): 973-984. (In Chinese)

[6] Ju Jinfeng, Xu Jianlin, Zhu Weibing. Longwall chock sudden closure incident below coal pillar of adjacent upper mined coal seam under shallow cover in the Shengdong coalfield [J]. International Journal of Rock Mechanics and Mining Sciences. 2015; 77: 192-201.

[7] Song Z.Q., Jiang J.Q. The current research situation and developing orientation of strata control in coal mine. Chinese Journal of Rock Mechanics and Engineering. 1996, 15(2):128-134. (In Chinese)

[8] Wang G.F., Pang YH. Surrounding rock control theory and longwall mining technology innovation. International Journal of Coal Science \& Technology. 2017; 4:301-309.

[9] Wang G.F., Pang Y.H. Shield-roof adaptability evaluation method based on coupling of parameters between shield and roof strata. Journal of China Coal Society. 2016; 41:1348-1353. (In Chinese)

[10] Schmitz Anne, Ye Mao, Shapiro Robert, et al. Accuracy and repeatability of joint angles measured using a single camera markerless motion capture system. Journal of Biomechanics, 2014, 47(2):587-591.

[11] DENNIS J. Black. Review of coal and gas outburst in Australian underground coal mines [J]. International Journal of Mining Science and Technology, 2019, 29:815-824.

[12] Qi Q.X., Pan Y.S, Li H.T. Theoretical basis and key technology of prevention and control of coal-rock dynamic disasters in deep coal mining. Journal of China Coal Society. 2020; 45(5):1567-1584. (In Chinese)

[13] Mu Hongwei, Song Dazhao, He Xueqiu, et al. Damage and fracture law of coal samples with different joint angles and their characterisation by acoustic emission. Structural Control and Health Monitoring, 2020, 27(12).

[14] BARCZAK Thomas M, CONOVER David P. NIOSH shield hydraulics inspection and evaluation of leg data (shield) computer program [A]. The 21 ${ }^{\text {st }}$ International Conference on Ground Control [C], West Virginia, 2002, 27-33.

[15] SANDFORD J, MAHONEY S, CONOVER D P, et al. Shield monitoring to forecast severe face weighting at the South Bulga Colliery, NSW, Australia[A]. The 18 International Conference on Ground Control in Mining[C], West Virginia, 1999, 164-175.

[16] TRUEMAN R, CALLAN M, THOMAS R, et al. Quantifying the impact of cover depth and panel width on longwall shield-strata interactions[A]. 2010 Underground Coal Operators' Conference[C], Wollongong, 2010, 97-107.

[17] TRUEMAN R, LYMAN G, COCKER A. Longwall roof control through a fundamental understanding of shieldstrata interaction [J]. International Journal of Rock Mechanics \& Mining Sciences, 2009, 46(2):371-380.

[18] TRUEMAN R, LYMAN G, COCKER A. Managing roof control problems on a longwall face [A]. 2008 Underground Coal Operators' Conference [C], Wollongong, 2008:10-21.

[19] DEB D. Development of the longwall strata control and maintenance system (LOSCOMS) [D]. Alabama: The University of Alabama, 1997.

[20] Yu B, Zhang Z, Kuang T, et al. Stress changes and 
deformation monitoring of longwall coal pillars located in weak ground. Rock Mechanics \& Rock Engineering. 2016, 49(8):3293-3305.

[21] Ding Xin, Xiao Xiaochun, Wu Di, Lv Xiangfeng. Mechanical properties and charge signal characteristics in coal material failure under different loading paths. International Journal of Coal Science \& Technology, 2019, 6(1): 138-149.

[22] Zhao Yang, Zhou Hongwei, Zhong Jiacheng, Liu Di. Study on the relation between damage and permeability of sandstone at depth under cyclic loading. International Journal of Coal Science \& Technology, 2019, 6(4): 479492.

[23] Xue Dongjie, Zhou Jie, Liu Yintong, Gao Lie. On the excavation-induced stress drop in damaged coal considering a coupled yield and failure criterion. International Journal of Coal Science \& Technology, 2020, 7(1): 58-67.

[24] Kang Hongpu, Lou Jinfu, Gao Fuqiang, et al. A physical and numerical investigation of sudden massive roof collapse during longwall coal retreat mining. Int J Coal Geol. 2018, 188:25-36.

[25] Peng Syd S. Longwall mining ( $2^{\text {nd }}$ Edition) [M]. Morgantown: 2006.

[26] Cheng Jingyi, Wan zhijun, Ji Yinlin. Shield-roof interaction in longwall panels: Insights from field data and their application to ground control [J]. Advances in Civil Engineering, 2018(12):1-18.

[27] Zhang Wenjie, Huang Tiwei. Current situation and prospect of China's coal mine safety regulation system [J]. Coal Mine Safety, 2020, 51(10):10-17. (In Chinese)

[28] Pang Yihui, Wang Hongbo, Zhao Jianjian, et al. Analysis and prediction of hydraulic support load based on time series data modeling [J]. Geofluids, 2020, ID:8851475.

[29] Conejo A J, Plazas M A, Espinola R, et al. Day-ahead electricity price forecasting using the wavelet transform and ARIMA models[J]. IEEE Transactions on Power Systems. 2005, 20(2): 1035-1042.

[30] Seyyede Z S, Seyyed A S. A fast and efficient pretraining method based on layer-by-layer maximum discrimination for deep neural networks. Neurocomputing, 2015; 669-680.

[31] Schar C, Vasilina L, Dirren S. Seasonal runoff forecasting using precipitation from meteorological data assimilation systems. Journal of Hydrometeorology. 2004; 5:959-973.

[32] Box Ge E P, Jekins G M, Reinsel G C, et al. Times series analysis, forecasting and control $[\mathrm{M}] .5^{\text {th }}$ edition. Hoboken, New Jersey: John Wiley \& Sons, 2016.

[33] Rehab Duwairi, Mohammed Abu-Rahmeh. A novel approach for initializing the spherical K-means clustering algorithm [J]. Simulation Modelling Practice and Theory, 2015, 54:49-63.

[34] Wang Jiachen, Wang Zhaohui. Stability of main roof structure during the first weighting in shallow highintensity mining face with thin bedrock. Journal of Mining \& Safety Engineering. 2015; 32:175-181.

[35] Pang Yihui, Wang Guofa, Yao Qiangling. Double-factor control method for calculating hydraulic support working resistance for longwall mining with large mining height. Arabian Journal of Geosciences. 2020, 13:252-265.

[36] Cheng Jinyi, Wan Zhijun, Peng Syd S, et al. Technology of intelligent sensing of longwall shield supports status and roof strata based on massive shield pressure monitoring data. Journal of China Coal Society, 2020, 45(6):2090-2103. 



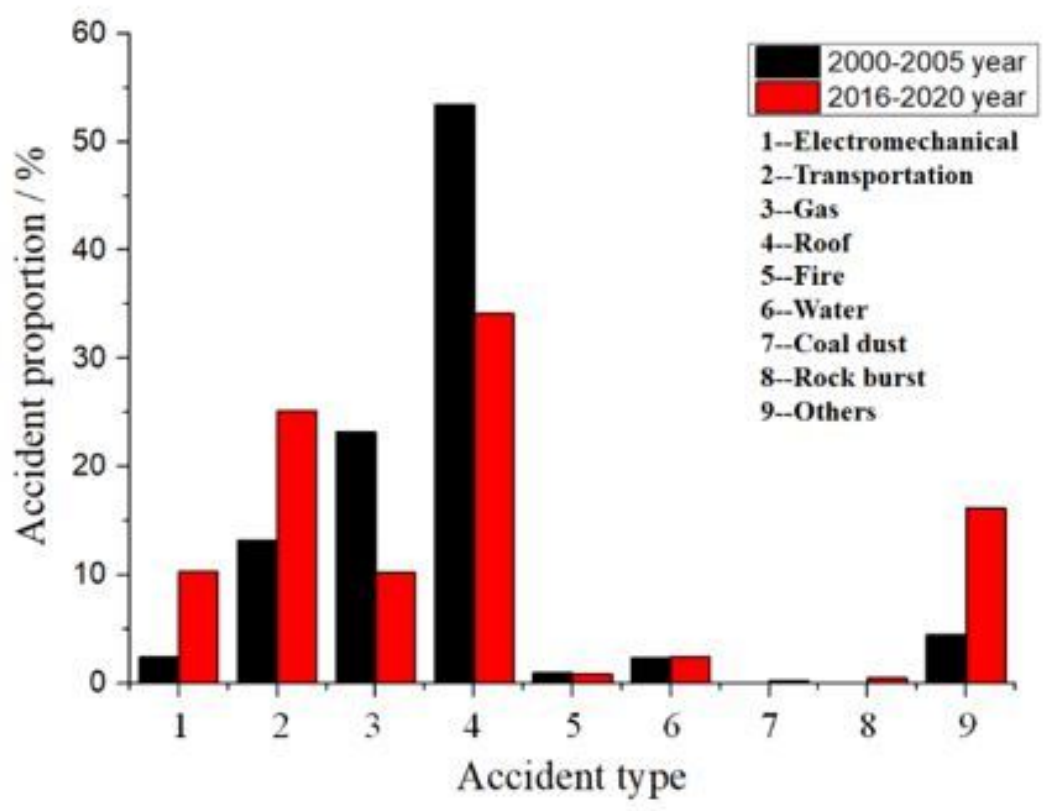

a. Changes in the number of coal mine safety accidents

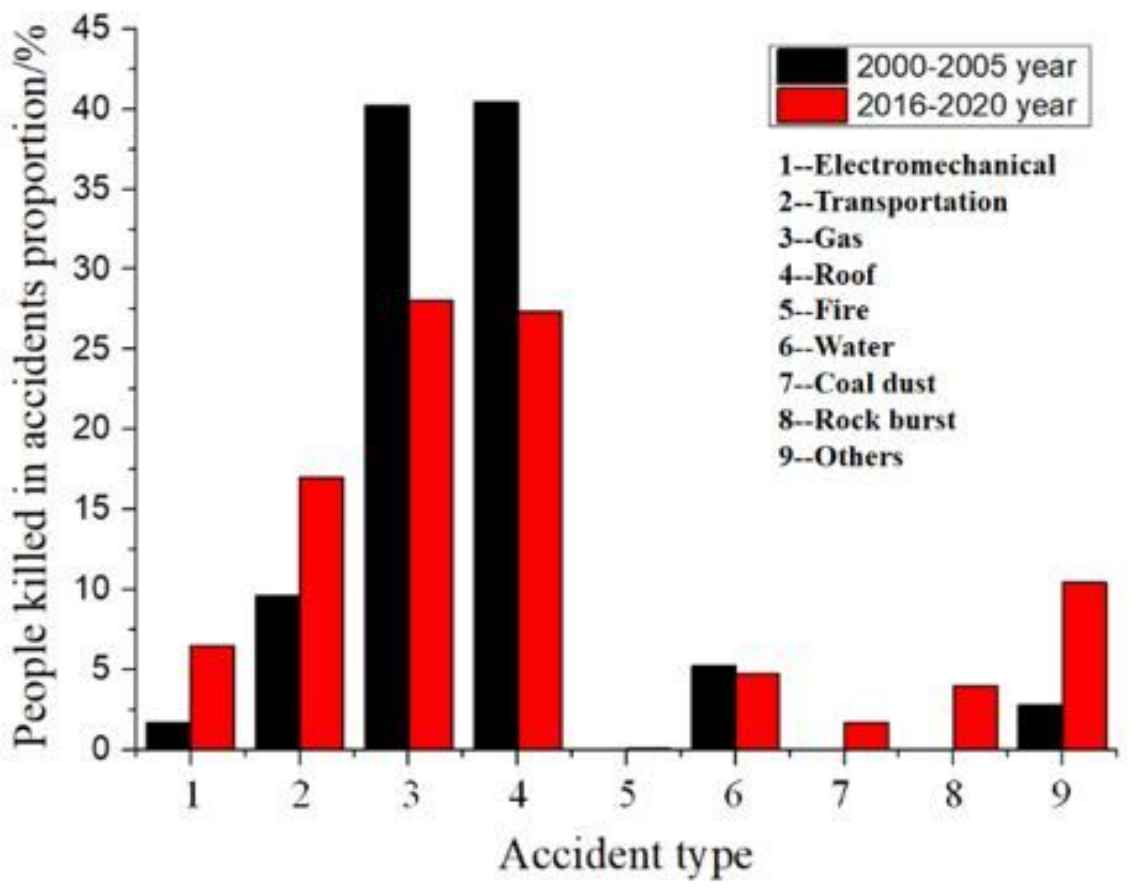

b. Changes in the death toll of coal mine safety accidents

\section{Figure 1}

Distribution of coal mine safety accidents in China 


\begin{tabular}{|c|c|c|}
\hline & $\begin{array}{l}\text { Inclination angle of hydraulic } \\
\text { support top beam }\end{array}$ & \\
\hline & $\begin{array}{l}\text { Inclination angle of hydraulic } \\
\text { support shield beam }\end{array}$ & $\begin{array}{l}\text { Hydraulic } \\
\text { support } \\
\text { posture }\end{array}$ \\
\hline $\begin{array}{l}\text { Characteristic } \\
\text { parameters of }\end{array}$ & $\begin{array}{l}\text { Inclination angle of hydraulic } \\
\text { support base }\end{array}$ & \\
\hline $\begin{array}{l}\text { roof disaster } \\
\text { monitoring }\end{array}$ & $\begin{array}{l}\text { Advanced position of } \\
\text { longwall face }\end{array}$ & \\
\hline $\begin{array}{l}\text { information of } \\
\text { longwall face }\end{array}$ & $\begin{array}{l}\text { Relative attitude of hydraulic } \\
\text { support and roof }\end{array}$ & \\
\hline $\begin{array}{l}\text { based on } \\
\text { hydraulic }\end{array}$ & Hydraulic support column load & Setting load \\
\hline support pose - & Balance column load & Load increase \\
\hline load variation & Balance column displacement & rate \\
\hline & $\begin{array}{l}\text { Front beam column load (Hinged } \\
\text { front beam construction) }\end{array}$ & $\begin{array}{l}\text { Cycle end } \\
\text { resistance }\end{array}$ \\
\hline & Front beam column displacement & Cycle time \\
\hline & (Hinged front beam construction) & Safety valve \\
\hline & Lower shrinkage of column & opening \\
\hline
\end{tabular}

Figure 2

Monitoring information characteristic parameters of longwall face roof disaster 


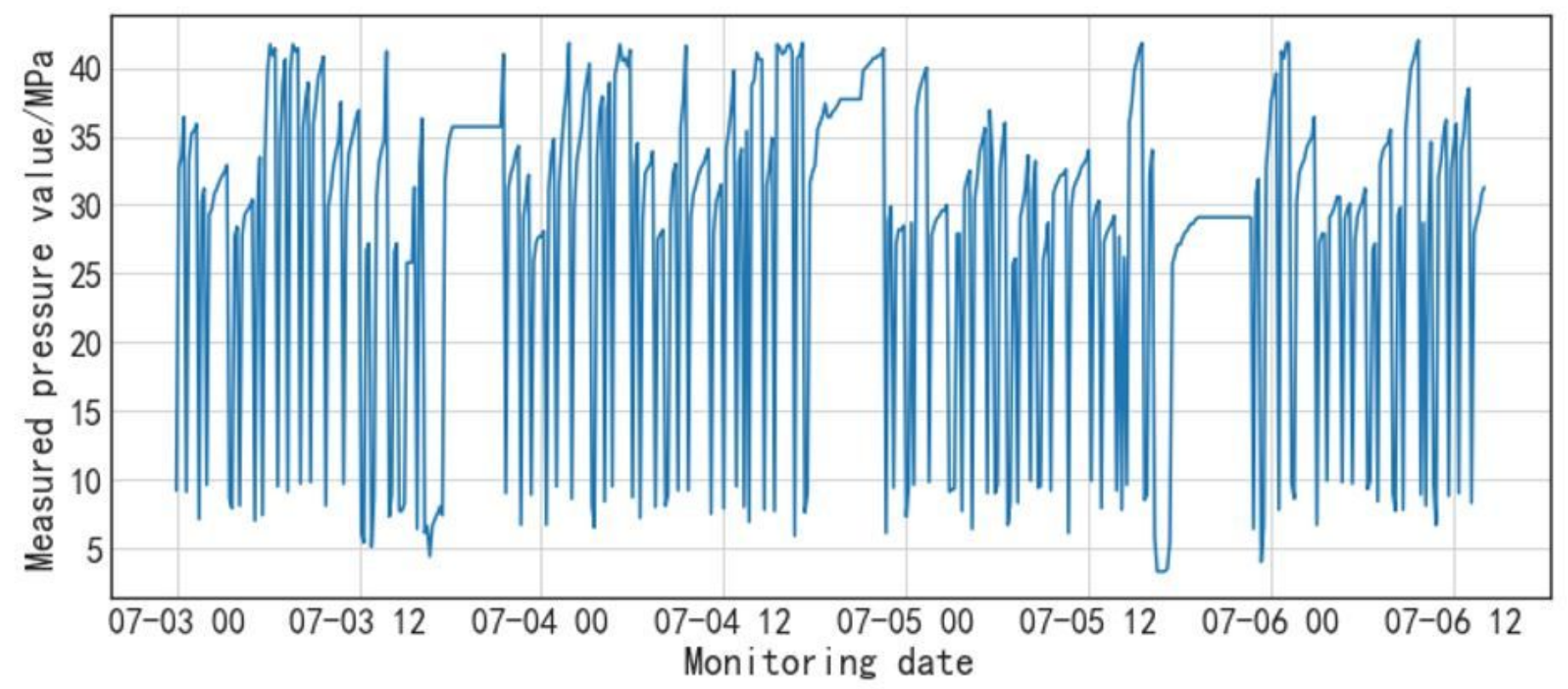

Figure 3

Monitoring load of hydraulic support 


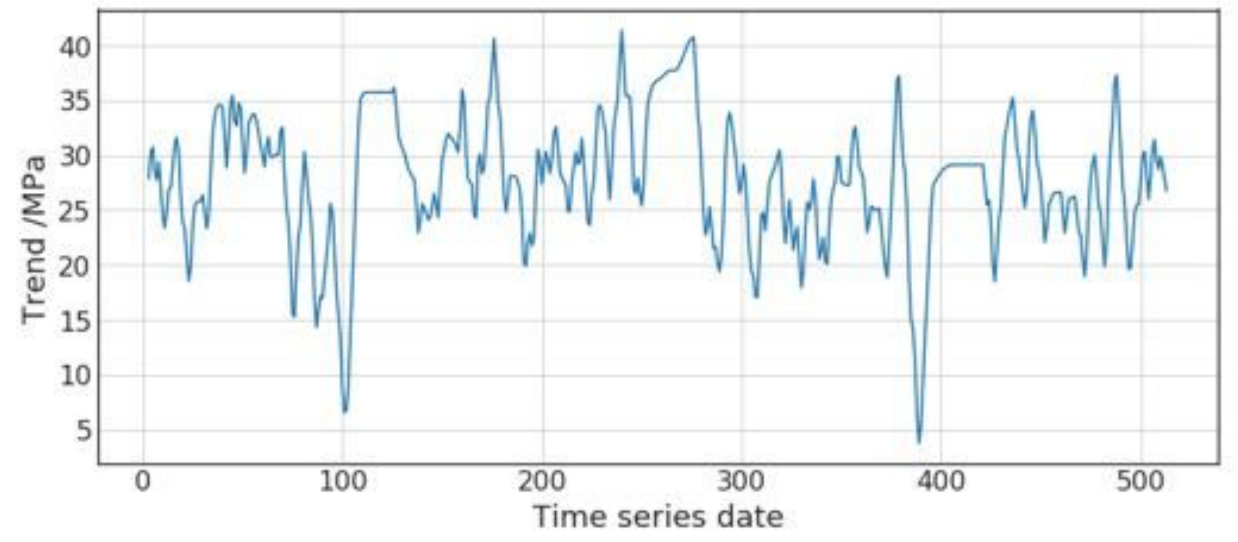

a. Trend item of support load change

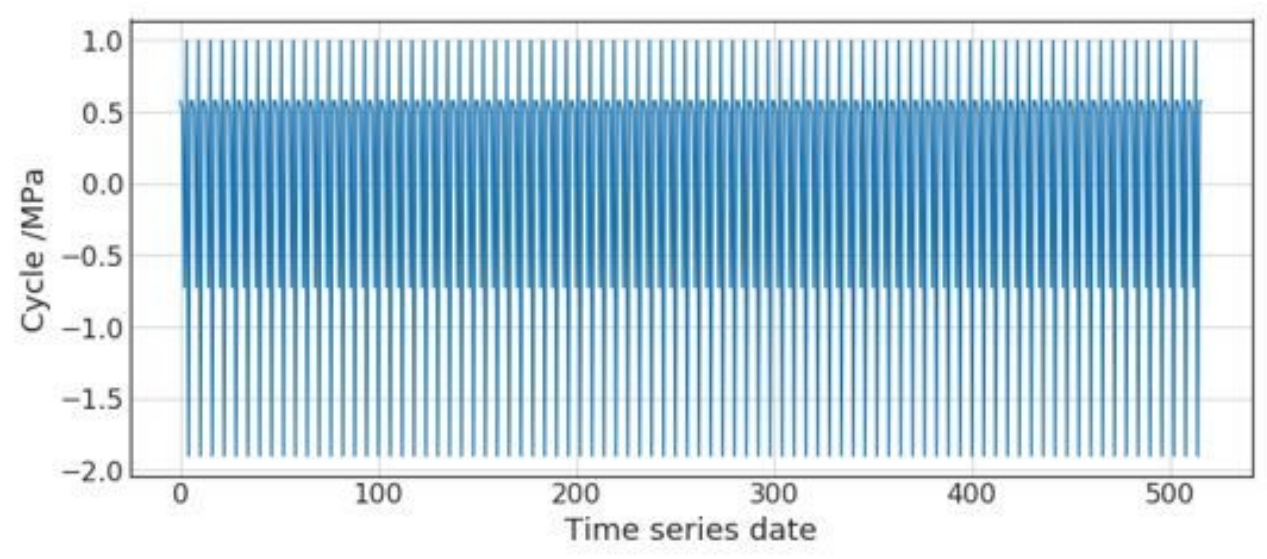

b. Cycle period item of support load change

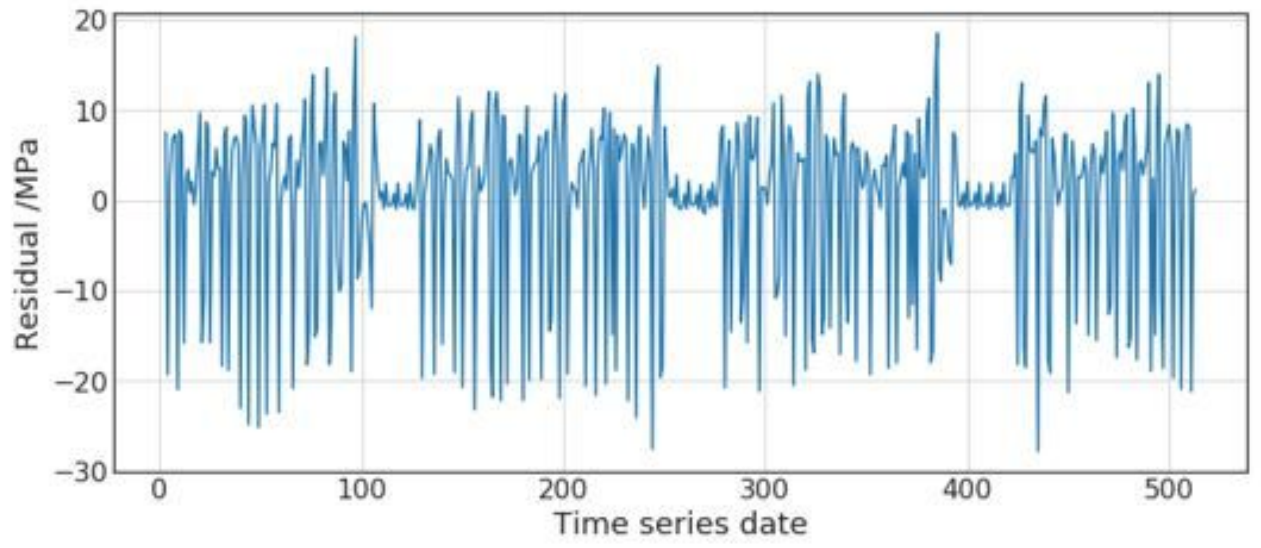

c. Residual item of support load change

Figure 4

Feature decomposition of monitoring support load 


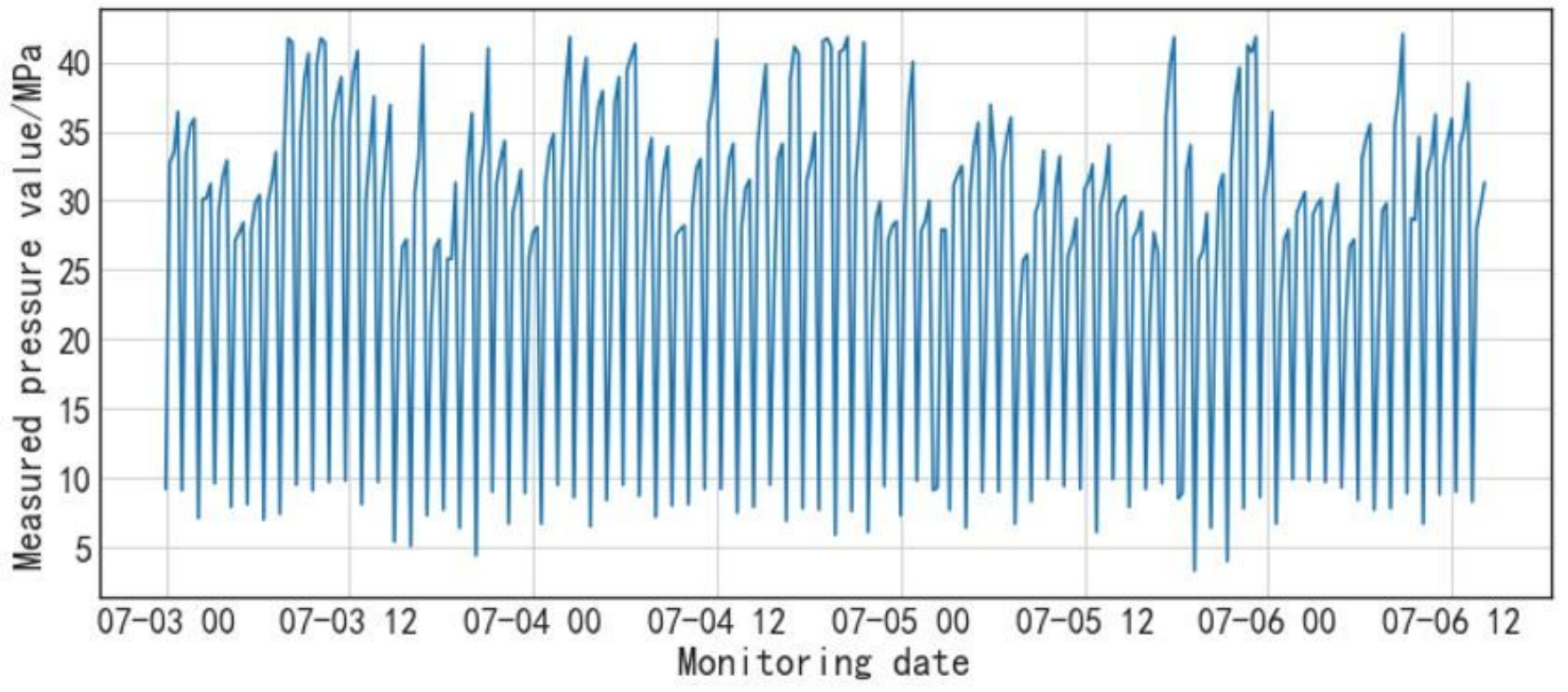

Figure 5

Preprocessed load data of support 


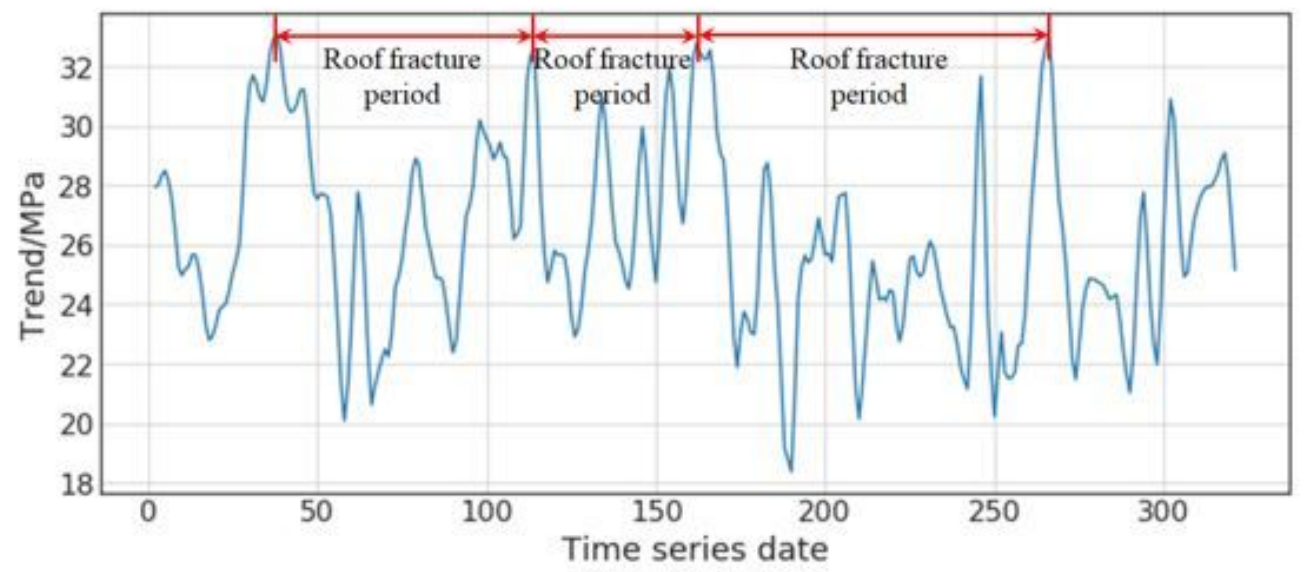

a. Trend item of support load change

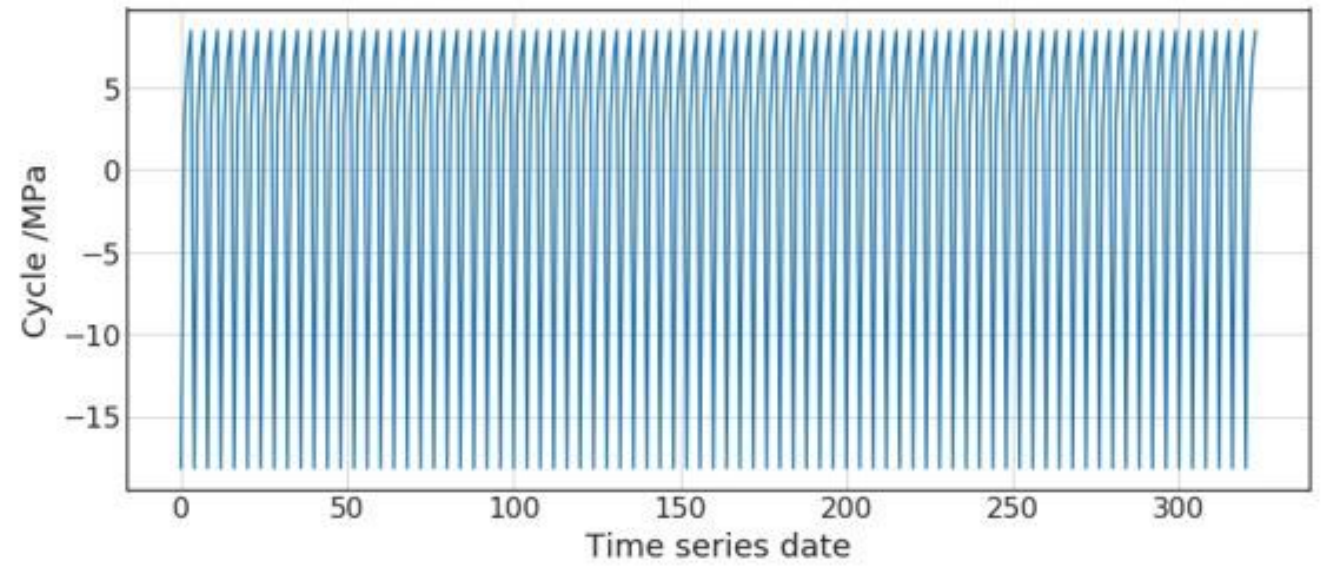

b. Cycle period item of support load change

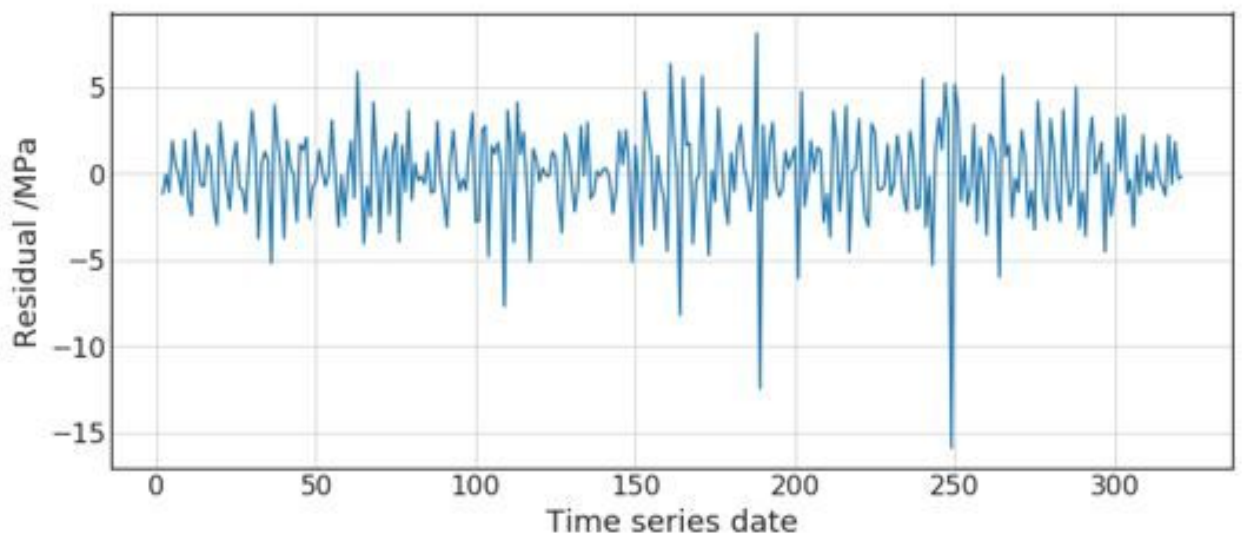

c. Residual item of support load change

Figure 6

Feature decomposition of preprocessed monitoring support load 


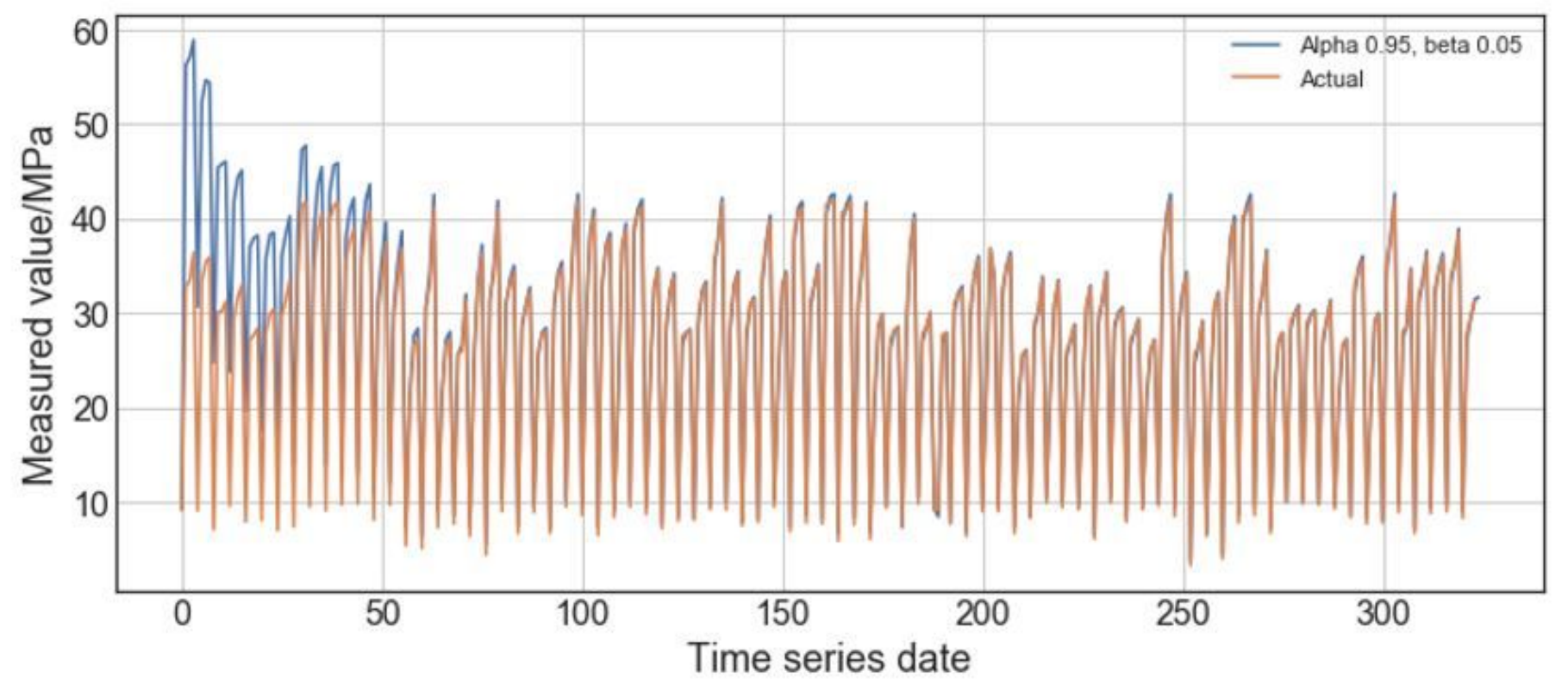

Figure 7

Support load prediction based on the double exponential smoothing algorithm

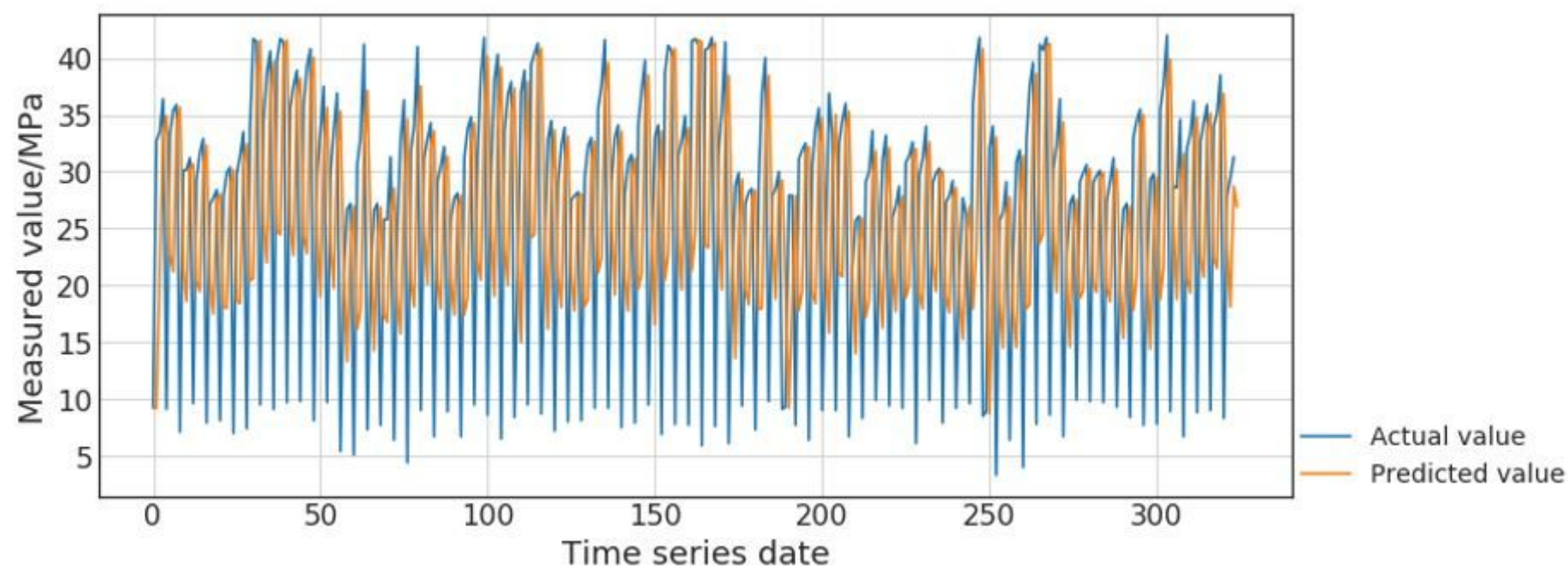

Figure 8

Support load prediction based on the sliding window model 


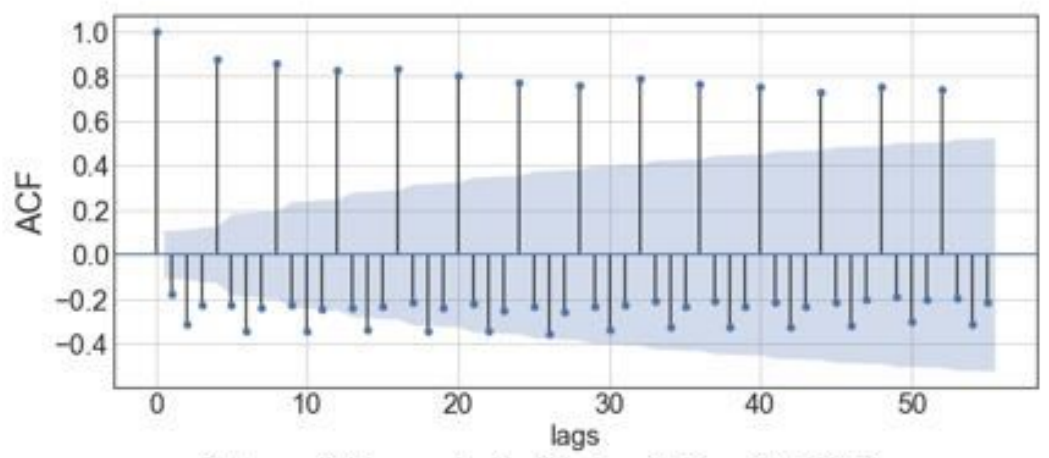

a. Autocorrelation graph of original monitoring data ( $\mathrm{ACF}$ )
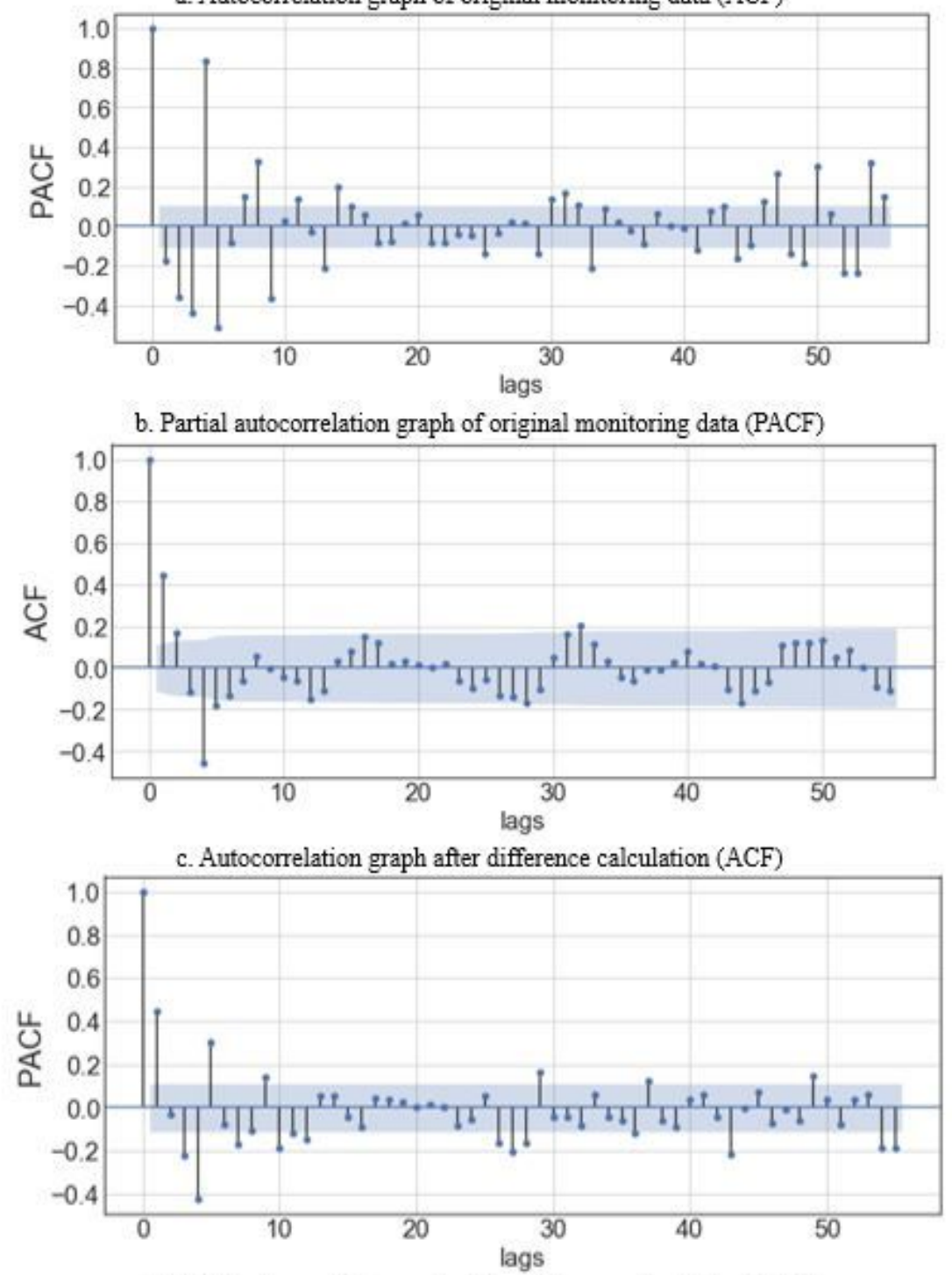

d. Partial autocorrelation graph after difference calculation (PACF)

\section{Figure 9}

Autocorrelation graph and partial autocorrelation graph of monitoring data before and after differential calculation 


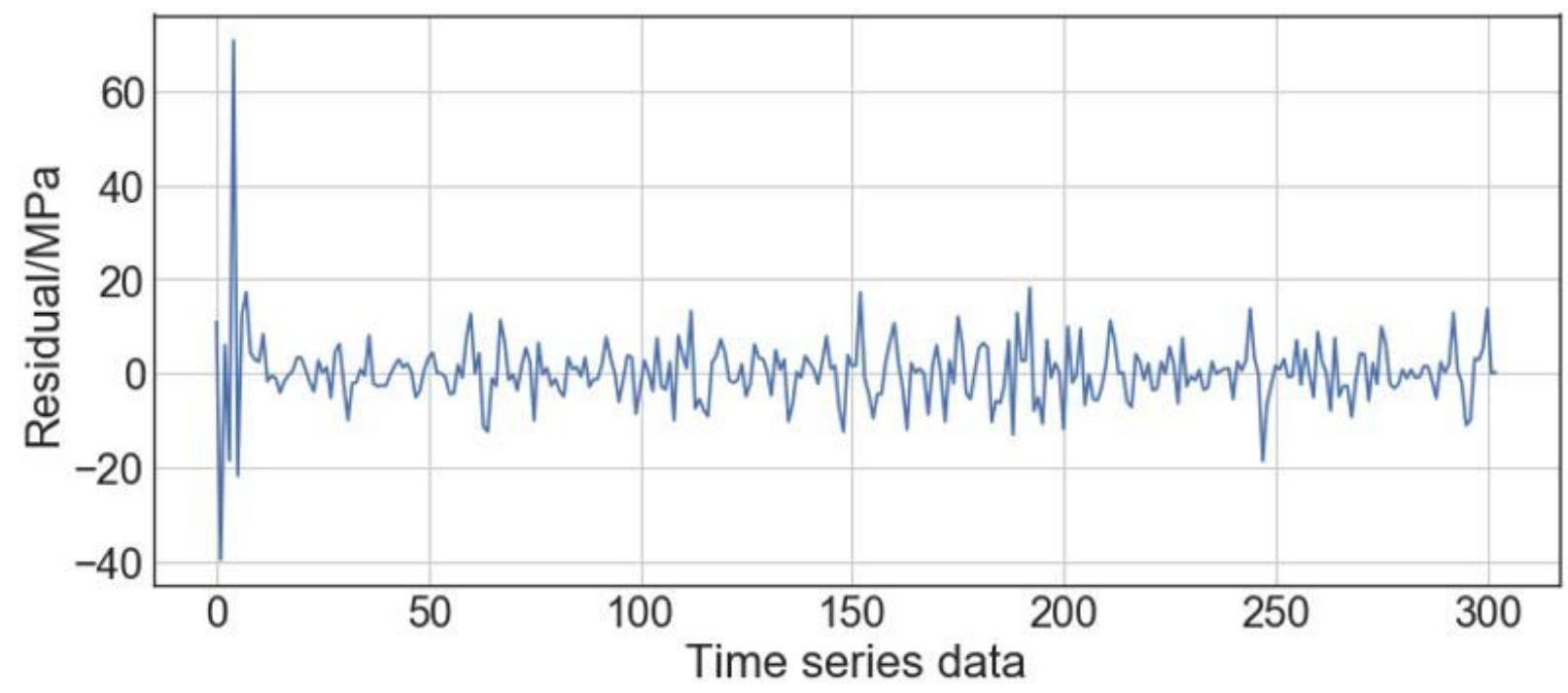

Figure 10

Residual value of model optimization 


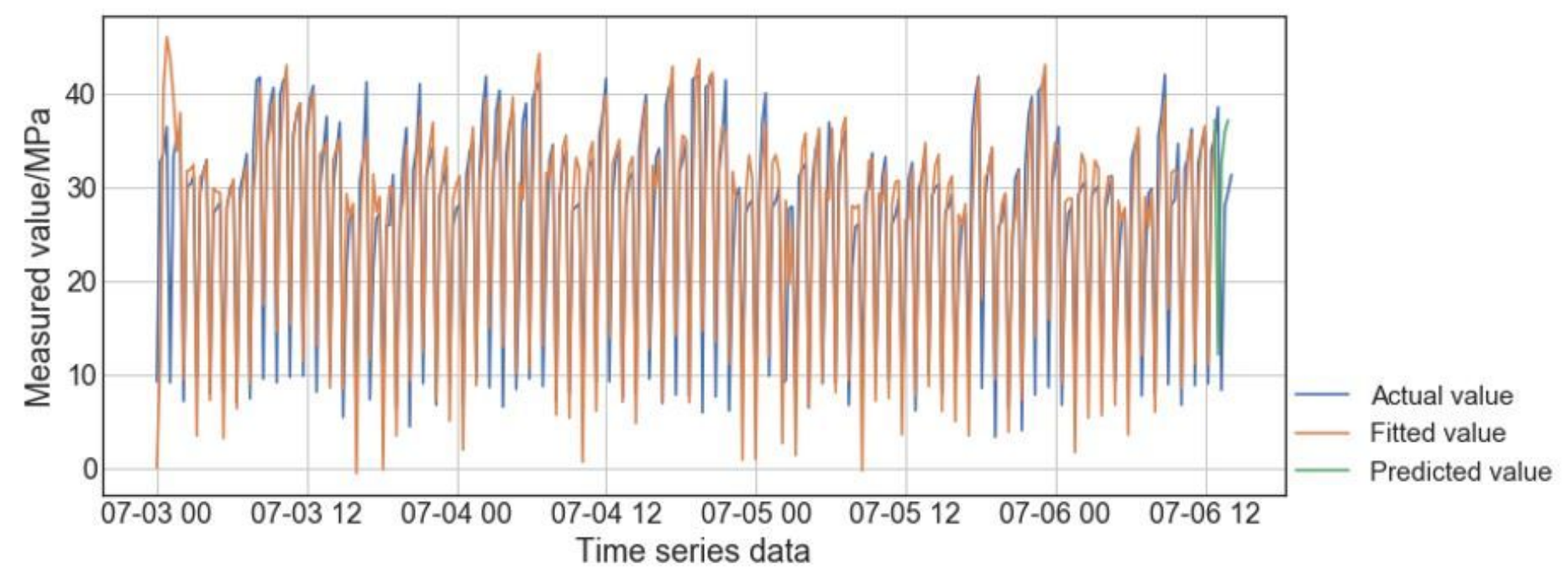

a. Overall fitting result

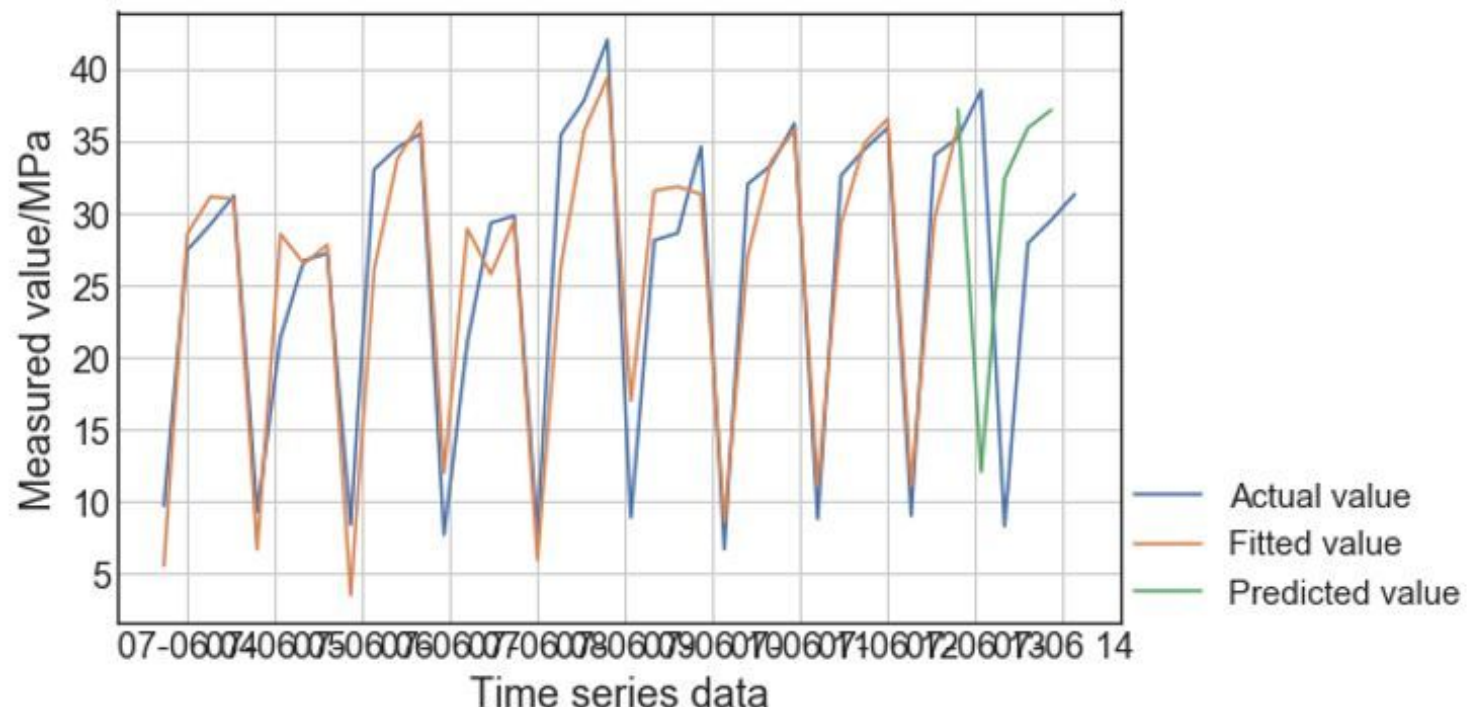

b. Local fitting result

Figure 11

ARIMA model fitting result 


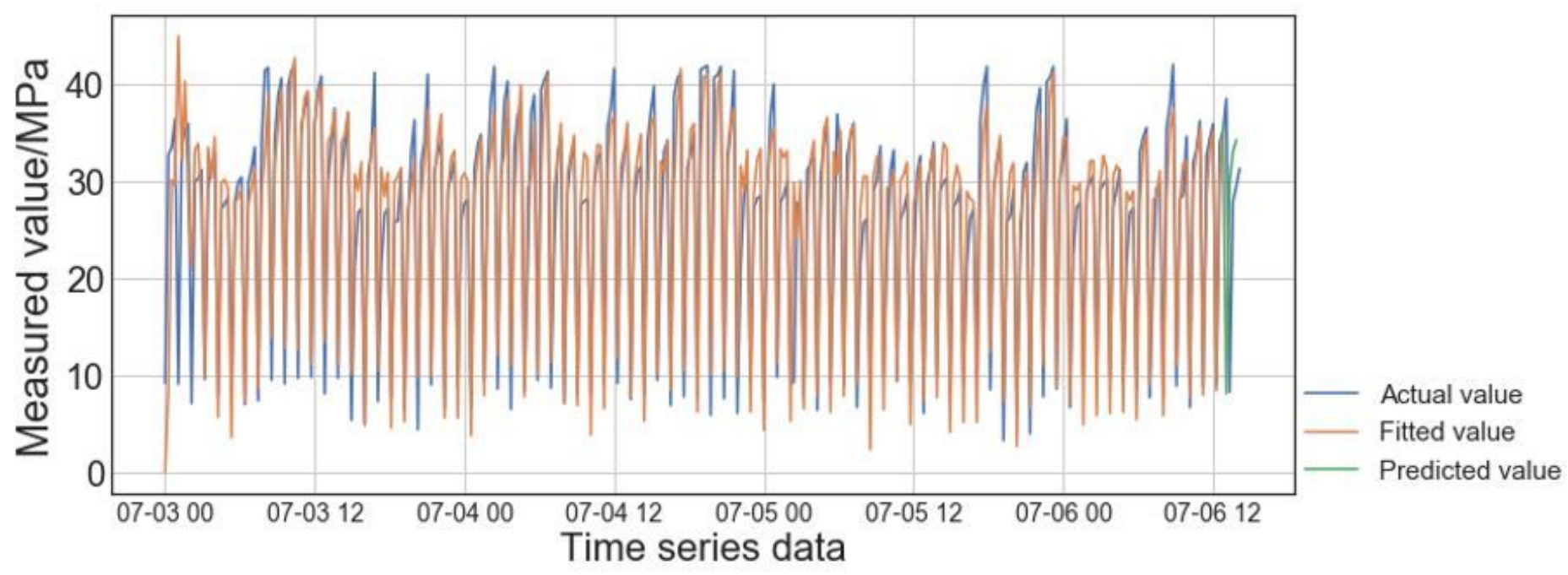

a. Overall fitting result

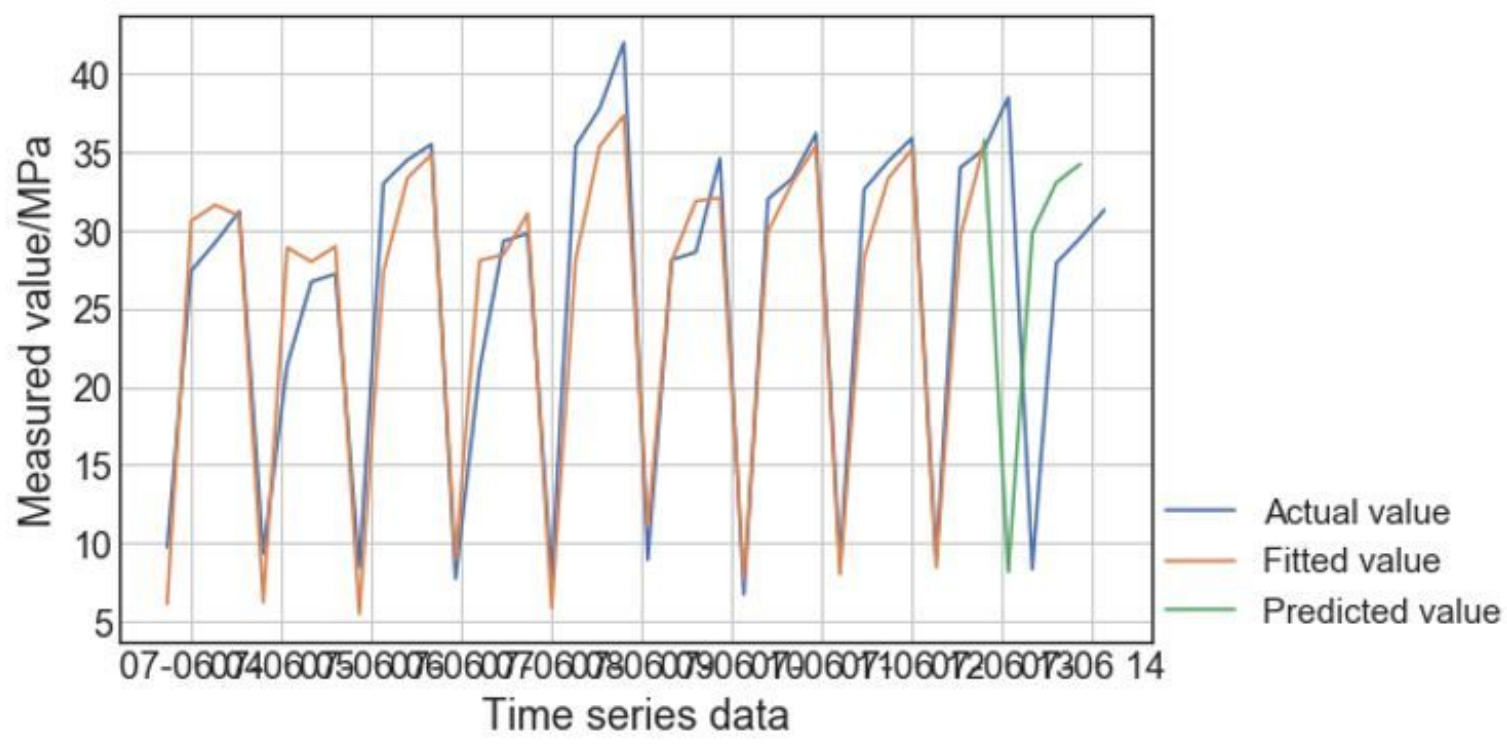

b. Local fitting result

Figure 12

SARIMA model fitting result 


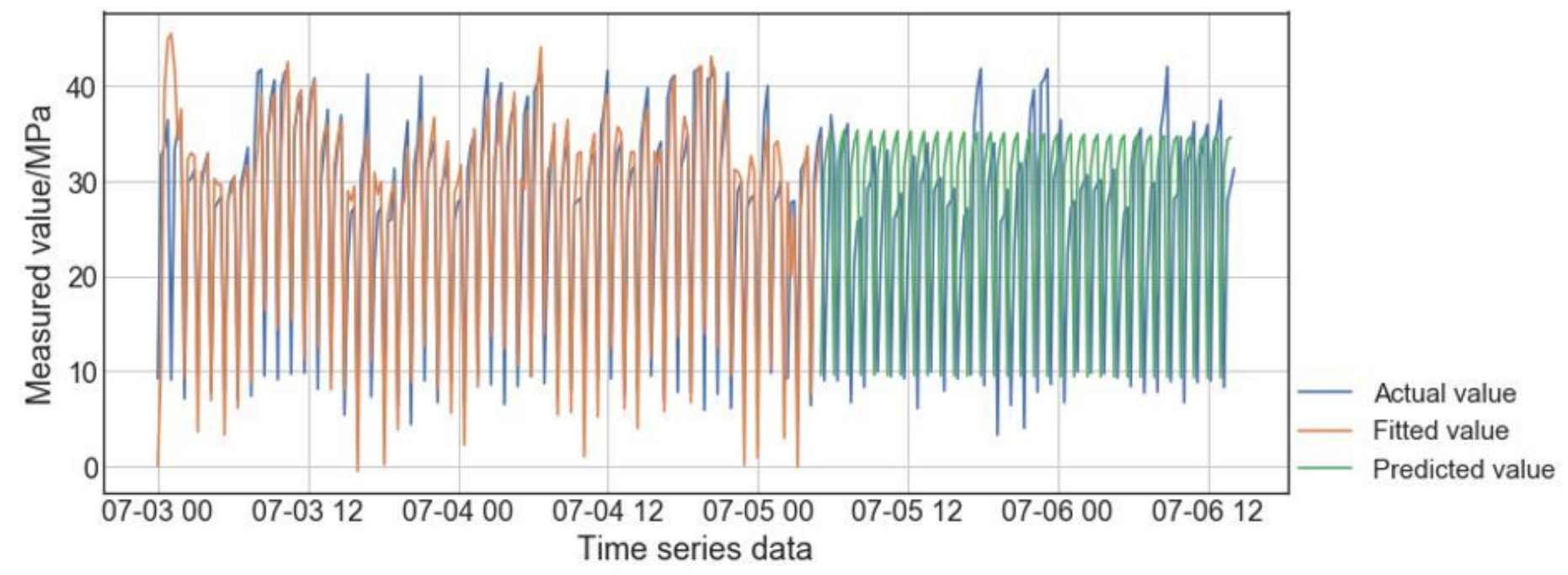

a. ARIMA model

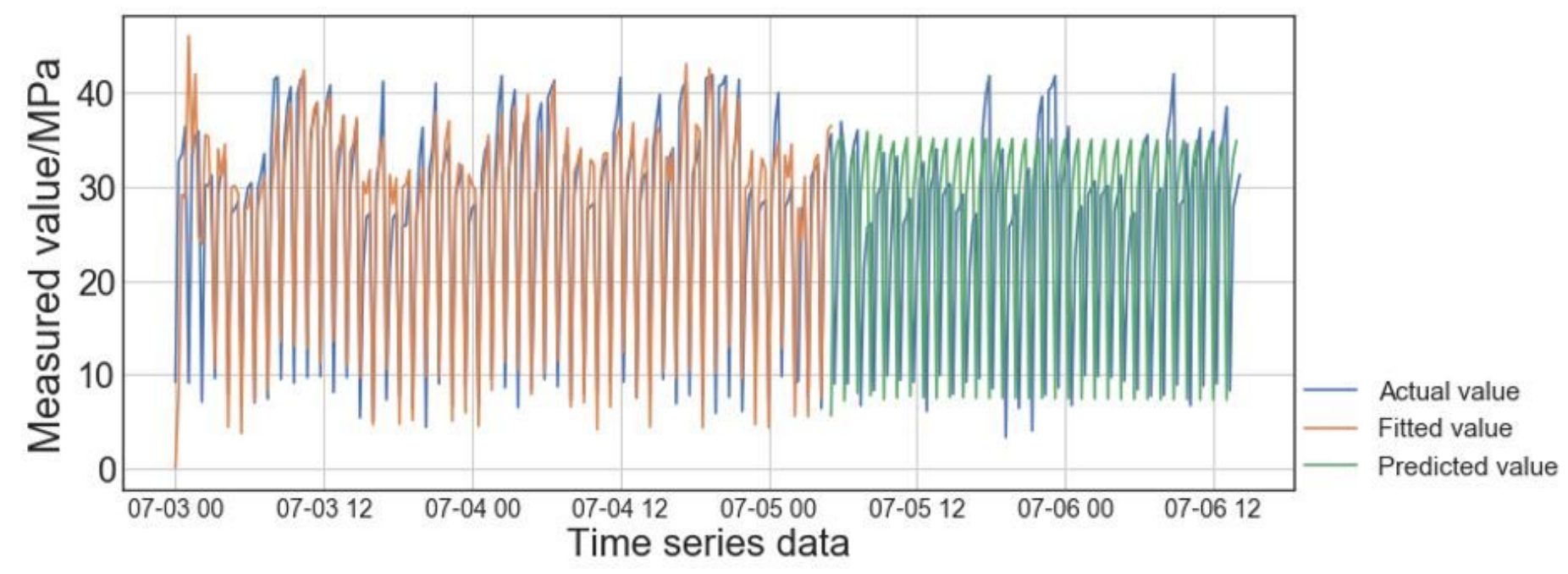

b. SARIMA model

Figure 13

Different models to predict the support load in multiple cycles 


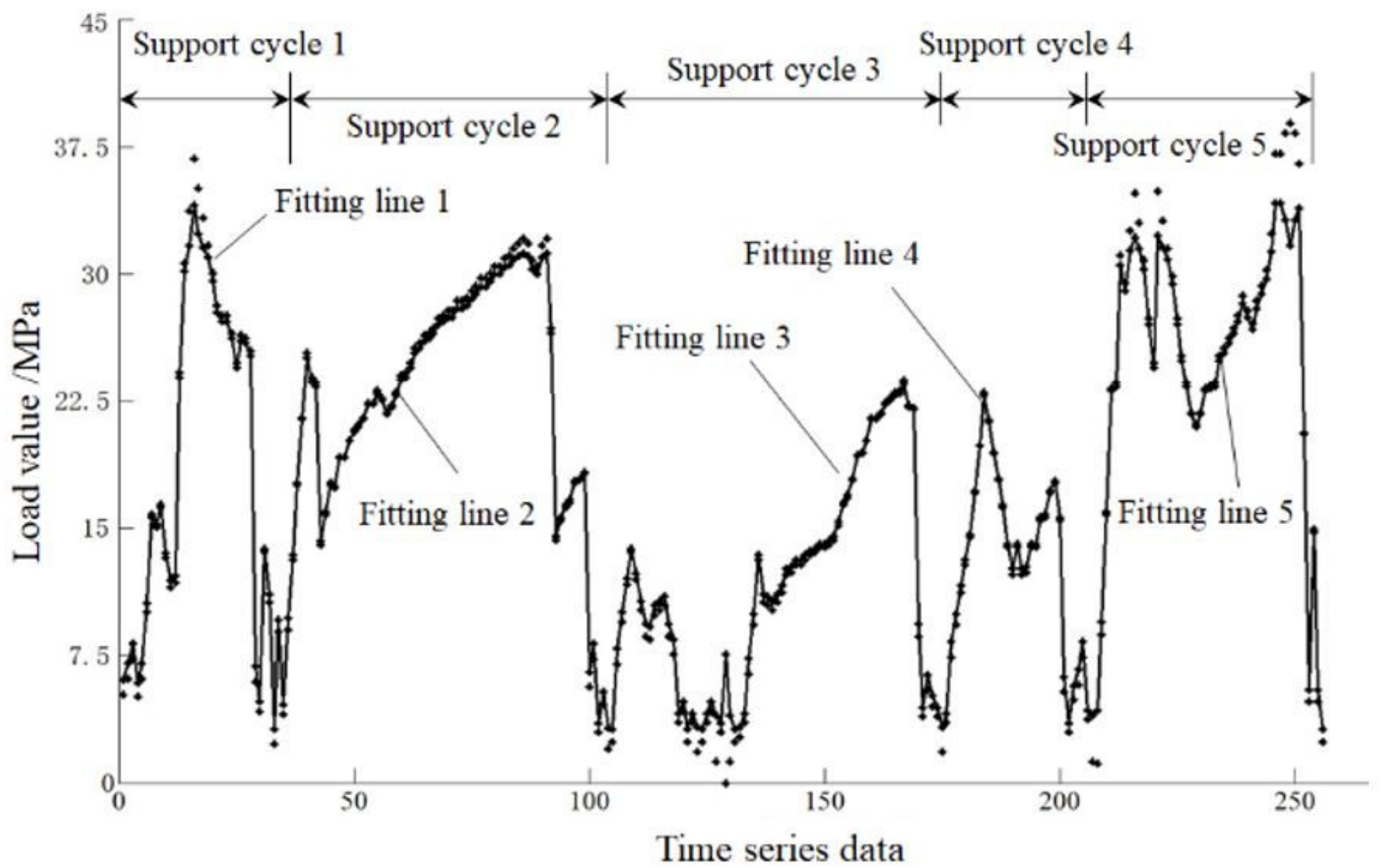

Figure 14

Sequence of support load template curves for one fracture cycle of roof strata 


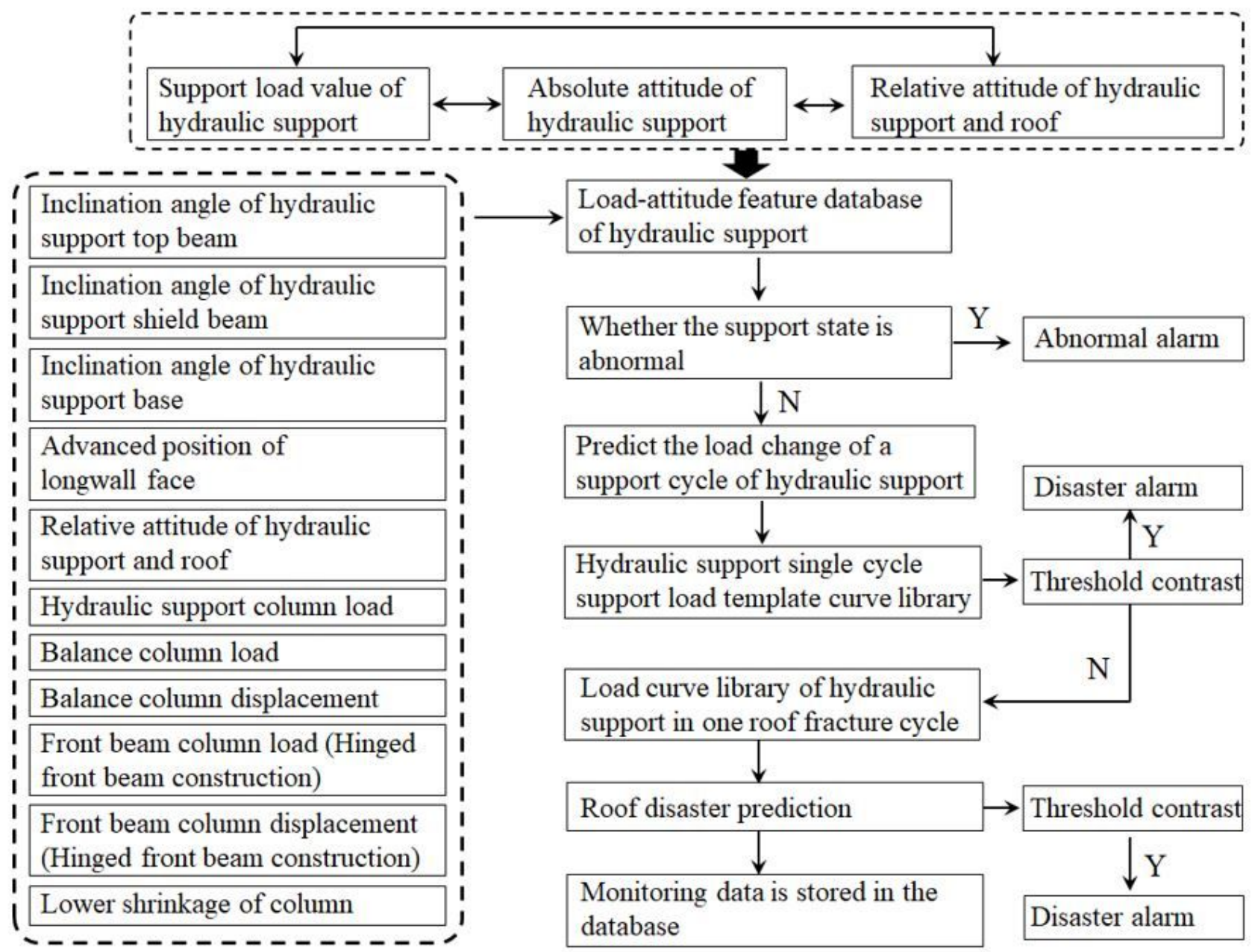

\section{Figure 15}

The technical framework of intelligent prediction platform for roof disaster 